\title{
Which Societies Provide a Strong Religious Socialization Context? Explanations Beyond the Effects of National Religiosity
}

Tim Müller, Nan Dirk De Graaf and Peter Schmidt

\author{
Linköping University Post Print
}

Tweet

N.B.: When citing this work, cite the original article.

Original Publication:

Tim Müller, Nan Dirk De Graaf and Peter Schmidt, Which Societies Provide a Strong Religious Socialization Context? Explanations Beyond the Effects of National Religiosity, 2014, Journal for the Scientific Study of Religion, (53), 4, 739-759.

http://dx.doi.org/10.1111/jssr.12147

Copyright: Wiley: 24 months

http://eu.wiley.com/WileyCDA/

Postprint available at: Linköping University Electronic Press

http://urn.kb.se/resolve?urn=urn:nbn:se:liu:diva-113172 


\title{
Which societies provide a strong religious socialization context? Explanations beyond the effects of national religiosity
}

\author{
Tim S. Müller - Institute for Analytical Sociology, University of Linköping \\ Nan Dirk de Graaf - University of Oxford, Nuffield College \\ Peter Schmidt - Higher School of Economics (HSE), Moscow
}

Submission date: 23 July 2013

Re-submission date: 18 February 2014

Article first published online: 3 December 2014

Word count: 10735 (excluding appendices)

Disclaimer: This is the peer reviewed version of the following article: Müller, Tim, Nan Dirk de Graaf, and Peter Schmidt. 2014. "Which societies provide a strong religious socialization context? Explanations beyond the effects of national religiosity." Journal for the Scientific Study of Religion 53(4):739-759, which has been published in final form at http://onlinelibrary.wiley.com/doi/10.1111/jssr.12147/abstract. This article may be used for non-commercial purposes in accordance With Wiley Terms and Conditions for self-archiving.

Acknowledgements: The authors would like to thank the anonymous reviewers as well as Thomas Grund, Per Block, Kenisha Russell Jonsson, and Niels Selling for helpful comments and suggestions.

Further comments: All data analyzed in this paper is publicly available. Sources and information about where to access the data are included in the text. Results of further analyses are available from the authors on request. Please note that additional results are contained in the appendix, which is made available as online supplement via the publisher. Please direct your correspondence to Tim Müller, Linköping University, Institute for Analytical Sociology, 60174 Norrköping, Sweden. E-mail: tim.muller@liu.se 


\title{
Which societies provide a strong religious socialization context? Explanations beyond the effects of national religiosity
}

NOTE: Footnotes are indicated by numbers in brackets and provided at the end of the manuscript.

\begin{abstract}
Religious socialization occurs within the immediate family as well as in the broader social context. Previous research has shown that parents' religiosity matters less for the transmission of religious beliefs in devout than in secular nations, implying smaller costs of religious socialization. In this paper we test which other societal factors affect the transmission of religious beliefs: anti-religious policies in formerly socialist countries, economic development, and income inequality. Our results indicate that societies with high levels of income inequality seem to provide the most favorable context for religious socialization. Individuals develop strong religious beliefs even if they only received little religious socialization within the family. Formerly socialist nations increased socialization costs through the overall suppression of religious practice. Economic development has no impact on socialization effects, suggesting that inequality is a more important driver of religious change than previously thought.
\end{abstract}

\section{Introduction}

The transmission of values and beliefs from one generation to the next is a fundamental problem that any religion, or other cultural practices, face (Bisin and Verdier 2000; Bengtson et al. 2009). In the field of sociology of religion this problem has mostly been treated in classical secularization theory (Berger 1969; Berger and Luckmann 1969). Empirical investigations usually examine cohort changes in religiosity (Firebaugh and Harley 1991; Schwadel 2010; Voas and Doebler 2011). However, while cohort analyses are well-suited to 
investigate the temporal dimension of religious change, they are less suited to examine the impact of the societal context on individual religious beliefs and religious socialization.

In this article we want to turn our attention to the impact of the societal context on the intergenerational transmission of religious beliefs. The question is, which societal factors, apart from the general religiosity of a nation, will allow religious beliefs to be passed on easily, without any stronger efforts by the parents. We hypothesize that a country's former belonging to the communist bloc, levels of economic development, and income inequality play a crucial role in this process, as they determine how costly religious socialization is. Based on previous research, we suggest that socialist state policies and economic development will increase the costs of religious socialization, whereas income inequality will lower the costs and provide a context in which religious beliefs are passed on easily.

Our approach is based on arguments first developed by Kelley and de Graaf (1997), who used a network explanation for the interpretation of their results. The authors found that the national religious context plays a crucial role in shaping individual religious beliefs independently of the religious socialization received through the parents. More importantly though, they found that parents' religious beliefs had a greater impact on their children's beliefs in secular as opposed to devout nations. Kelley and de Graaf's approach offers a very convenient and practical interpretation of the effects of religious socialization, which we will apply in this paper. When the impact of parents' religiosity on children's beliefs is high, this can be interpreted as an indicator of higher costs of religious socialization. When the parental effect is small, children seem to develop strong religious beliefs without stronger effort of the parents; socialization costs are therefore small.

The impact of the national religious context, using Kelley and de Graaf's network explanation, has been tested in a number of studies dealing with various topics, such as differences in religiosity between members of the same faith in different contexts (Lazerwitz 
and Tabory 2002), individuals' moral beliefs (Finke and Adamczyk 2008), volunteering behavior (Ruiter and de Graaf 2006), and attendance of religious services (Ruiter and van Tubergen 2009). All these studies confirm that the national religious context has an effect on its own and that effects of religious socialization are often moderated by it. A re-examination of Kelley and de Graaf's original argument makes sense because (1) new datasources and improved statistical methods help us to evaluate it more rigorously, and (2) it provides an opportunity to identify conditions beyond the religious context of nations that affect the transmission of religious beliefs.

This paper is structured as follows. We will discuss the original reasoning of Kelley and de Graaf's 1997 paper, give an overview about recent research on the role of the national religious context, and derive hypotheses regarding the costliness of religious socialization in different societal contexts from existing literature. We empirically test these hypotheses on three waves of ISSP survey data gathered in 41 nations (ISSP Research Group 1991, 1998, 2008), using multigroup confirmatory factor analysis and multilevel modeling. The findings suggest that levels of inequality play a strong role in the transmission of religious beliefs, which calls for a further investigation of the mechanisms behind this effect.

\section{Theory}

\subsection{The effect of the national religious context on religious socialization}

Kelley and de Graaf (1997) addressed the problem of how the societal context influences individuals' religious beliefs independently from the religious socialization one had received from their parents.[1] Based on network arguments they predicted that people living in religious nations should hold more orthodox beliefs, even when controlling for family background. They were able to confirm this hypothesis using individual level attitude data from 15 nations. The religious culture of a nation as well as a restricted pool of 
interaction partners in individuals' networks (there is a high chance of friends and potential spouses being religious) lead to higher individual religious beliefs (Kelly and de Graaf:640).

But the authors also predicted that socialization efforts of parents would matter differently in different religious contexts. They argued that parents of children born into religious nations have to invest less in the religious upbringing of their children because of the 'unchosen' religious context, which will affect their children as well. Kelley and de Graaf's results showed a weaker effect of parental religiosity on children's religiosity when these were raised in a devout nation compared to being raised in a secular nation. In societies, where everyone is religious, the religiosity of the parents does not matter as much for children's religiosity. However in very secular contexts, individual beliefs depend strongly on parents' religious beliefs. The authors attribute this finding to the fact that in secular nations, religious parents have to make more effort in order to create a favorable socialization context. This involves "the control of children's social environments", the "screening of potential friends, teachers and marriage partners" or the "enrolment of children in church clubs [or] religious schools" (Kelley and de Graaf 1997:641). The costs of religious socialization are therefore relatively high under these conditions. Conversely, in very devout societies, these screening processes are not necessary, since the larger environment is religious anyway. If religious socialization does not happen within the family, it is likely to happen within the larger society. This is a situation that could broadly be described by Berger's famous notion of a "sacred canopy" (Berger 1969). Accordingly, we can assume that the costs of socializing children into a religious worldview are low under these conditions.[2] We therefore re-state Kelley and de Graaf's hypothesis regarding the interaction of national religious context and effects of parents' religiosity:

H1. The strength of the association between parental religiosity and an individual's religiosity will be weaker in devout societies. 
However, while Kelley and de Graaf's explanation is well-suited to explain why religious societies retain their high levels of religiosity, it does not explain very well why societies secularize. A simple explanation would be that children are aqcuiring less religious beliefs because they are growing up in a more secular context. Yet, if strongly religious societies more or less allow a perfect transmission of religious beliefs, how is religious change induced? Therefore our analysis will pay closer attention to other contextual characteristics that should have an impact on the costs of religious socialization: anti-religious policies in former socialist countries, levels of economic development, and income inequality. Technically, we are not so much interested in the main effects of these factors (e.g. how average levels of beliefs are affected by economic development). We are more interested in how contextual characteristics interact with individals' religious socialization to produce a certain level of religious beliefs (e.g. does religious socialization through the parents matter more as economic development increases?). Accordingly, we will focus our discussion on theories that are able to explain these cross-level interactions in the next section.

\subsection{Increasing socialization costs through anti-religious policies}

Formerly socialist societies provide a good testing ground for our hypothesis that the transmission of religious beliefs outside of the family strongly depends on the social context. Almost all socialist societies experienced policies that aimed at the complete abolition of religion, following the framework of "scientific atheism". As a wide variety of work in various disciplines shows, this process of "politically forced secularization" (Meulemann 2004:49) has been fairly successful (Borowik 1997; Müller and Neundorf 2012; Nielsen 1991; Tomka 1994). The Churches were forced to give up the roles which they traditionally played in public education and social welfare, and religious organisations were monitored or prohibited (Froese 2004). Moreover, policies of state-supplied childcare and increased female labour participation eroded traditional family structures that are seen as the main vehicles of 
religious socialization (Myers 1996). We therefore hypothesize that the transmission of religious beliefs in ex-socialist societies was very costly and depended strongly upon the effort that parents were willing to undertake. Hence we should observe an increased effect of parental religious attendance on respondents' beliefs in formerly socialist countries:

H2. Ex-socialist societies suffered from a massive de-establishment of religious institutions and religious social capital. Hence we expect an increased impact of parental religious attendance on individuals' religious beliefs in ex-socialist societies.

\subsection{Increasing socialization costs in the course of modernization}

From a modernization perspective two arguments can be brought forward, concerning why religious beliefs should decrease with higher modernization levels, as well as why the effects of religious socialization should become more important. The first argument stems from a classical secularization perspective (Berger 1969; Berger and Luckmann 1966, 1969; Bruce 2002). Modernization will lead to a stronger division of labor and generally a stronger functional differentiation in all sub-systems of society. Religion ceases to provide an overarching "sacred canopy" as life-worlds become increasingly differentiated and religious diversity grows. The result is a relativization of religion, and ultimately, secularization.

The second argument can be derived from a deprivation perspective, most prominently represented by Norris \& Inglehart's “existential security hypothesis" (Norris and Inglehart 2004). The demand for religious value systems is determined by the levels of experienced "existential security" in the respondents" formative years or current life situation: "Individuals experiencing stress have the need for rigid, predictable rules" (Norris and Inglehart 2004:19). Thus societies that cannot provide their citizens with a minimal level of existential security are also societies where the demand for religious values seems to be highest. Religion therefore acts as a coping resource or welfare provider. A number of studies has found important effects of economic development or welfare spending on religious beliefs (Gill and Lundsgaarde 2004; Gruber 2004; Hungerman 2005; Scheve and Stasavage 2006a, 2006b). 
From the classical as well as from the existential security framework follows that religious socialization will be more costly as societies modernize. The "sacred canopy" that provided religious legitimization and socialization outside of the family will be eroded through functional differentiation. Moreover, as living conditions improve, the psychological need for religion decreases, and the role of religious socialization within the family becomes stronger. We derive the following hypothesis:

H3. Higher economic development will increase the impact of religious socialization within the immediate family context. Therefore we expect a positive interaction effect of GDP per capita and parental religious attendance on individuals' religious beliefs.

\subsection{The effects of inequality on religious socialization}

Previous research found that income inequality is a strong predictor of religiosity (Norris and Inglehart 2004; Müller 2009; Solt, Habel, and Grant 2011). While we are not able to identify the mechanism that links inequality to religiosity in this article, we are at least able to establish whether inequality provides a benefical environment for the transmission of religious beliefs.[3] There are at least three reasons why this should be the case: deprivation, political legitimization and social capital.

The deprivation argument is the same as described in the previous section (Norris and Inglehart's existential security hypothesis). Income inequality is a major source of material and psychological insecurity because unequal societies are, most of the time, also societies where social welfare systems deliver only rudimentary services and where individual risks are not universally covered by a safety net.

Another argument is derived from the political economy literature. Huber and Stanig (2007) and Glaeser et al. (2005) suggest that there might be political incentives to create inequality along religious lines. Recent work conducted by Solt and colleagues (2011) suggests that religion is mainly used to legitimize existing inequality. Religion is not only a source of comfort for the poor but rather a tool for the privileged to exert social control and 
shape mass attitudes. Therefore in unequal societies everyone holds strong religious beliefs, albeit for different reasons.

Religion's capability to act as a source of social capital is another argument why religious socialization should work efficiently in unequal societies. While strongly religious societies usually show lower levels of generalized trust (Bjornskov 2007; Uslaner and Brown 2005), religion might still facilitate exchange among particular others - members of the extended family, friends and colleagues (Rose 2000:149; You and Khagram 2005).[4] Membership of religious organisations will often allow access to co-religionists with desirable information or resources, as has been shown by Wuthnow (2002) for the US case. Other work has stressed this networking value of religion as well (Maselko, Hughes, and Cheney 2011; Sacerdote and Glaeser 2001; Stroope 2011; Traunmüller 2009).

All three arguments suggest that religious beliefs should not only be stronger in more unequal societies, but also that inequality provides a context in which religious beliefs are easily transmitted outside of the family context. New generations will experience insecurity and develop a need for religion independently from the religiosity of their parents, or social norms exist which suggest that religion is a beneficial force that will help to meet 'the right people'. In either case, we expect that the effect of parents' religiosity on individual religious beliefs is decreased in socities with higher levels of income inequality:

H4. The higher the income inequality in a society, the smaller the effect of parents' religious attendance on religious beliefs will be.

\section{Data and operationalization}

Similar to Kelley and De Graaf (1997) we use the 1991 data from the "Religion" module of the International Social Survey Programme (ISSP) and extend it with the 1998 and 2008 surveys (ISSP Research Group 1991, 1998, 2008). By this we increase the number of countries from 15 to 41 , and for 27 countries we have more than one cross-sectional wave. However, we limit our sample to countries with a predominantly monotheistic religious 
culture as our belief measurement is clearly biased towards monotheistic beliefs (see below). In total we have 105,087 individual cases with non-missing data on all relevant variables.[5]

\section{Measurement of religious belief}

Except for minor changes, we use the same religious belief scale which was used in Kelley and De Graaf's 1997 paper and which conceptually and empirically resembles standard religious orthodoxy scales used in previous research (van der Slik, de Graaf, and Peters 1994). It measures belief in a supernatural being who is concerned with each individual human personally. Table 1 shows the questionaire items used as well as the distribution of respondents in the different belief categories. Because of the monotheistic conception of the qustionnaire items we decided to limit our sample to countries belonging to traditional monotheistic religious traditions (Roman Catholicism, Protestantism, Orthodox Christianity, Islam, and Judaism). Within those societies we did not exclude believers of other faiths, but statistically controlled for their religious identification using dummy variables.

We score respondents' answers on each item conveniently in equal intervals, from a minimum of 0 ('do not believe in God') to a maximum of 100 ("believe and have no doubts"). Our religious orthodoxy scale is the average of answers to the three dimensions Degree of Belief, Belief Duration and Caring God.[6] Respondents who answered some but not all questions are assigned the average of the questions they did answer. Those who failed to answer any of the questions ( 1 percent) are omitted from the analysis.

The three belief items are highly correlated in all 41 nations, suggesting that they all measure a single underlying factor. In the pooled sample, inter-item correlations average .73 with a scale reliability (alpha) of .89. Factor loadings[7] average .91 in the pooled analysis, with equally high figures in separate analyses for each country. However, in order to ensure comparability over all 41 countries, we performed a Multiple Group Confirmatory Factor Analysis (MGCFA, see Appendix I). The results confirm that all factor loadings of the scale 
items achieve partial invariance across countries and time points. This is sufficient to establish equal meaning over time and countries (Byrne, Shavelson, and Muthén 1989).

\section{-TABLE 1 ABOUT HERE-}

\section{Parents' religious attendance}

We measure the religious socialization that every respondent has received by a proxy, due to lack of any better measurements. Our proxy is the respondent's mother's and father's religious attendance when the respondent was 11 or 12 years old. The underlying idea is that persons that show a high public observance of religious rites will also teach their children about the contents of their religious beliefs and make sure that children grow up in a religious framework (Kelley and de Graaf 1997:640). There are at least two justified criticisms against the use of this measure.

Firstly, we include persons in our analysis who have been raised in religious traditions where the attendance of religious services has not a significant meaning as it does in (Catholic) Christianity. However, in most religious traditions considered in our sample, public observance of religious rites is common and could be considered a measurement of strength of religious identification (such as festivals or shrine visits in Buddhism and Shintoism in Japan and Korea or Buddhism and Taoism in Taiwan). Please bear in mind that after the exclusion of Japan, South Korea and Taiwan, only $1 \%$ of respondents in our sample belong to these Eastern religious traditions. We therefore assume the potential bias to be small.

The second criticism is that even within monotheistic religious traditions the attendance of religious services has fundamentally different meanings. As such, mass attendance in Roman Catholicism was obligatory and non-attendance considered a grave sin up to the second Vatican Council. Since then, the devotion to the Eucharist has been emphasised more strongly (Martin 2005:119). Religious attendance is considered less important in Protestantism, and the observance of the salat (five daily prayers) in Islam would 
be more indicative of the religiosity of a Muslim believer. We answer this criticism by pointing out that, in an earlier version of this paper, we considered all the effects for Catholics and Protestants separately. While there are differences in the effects between those two groups, it became clear that there is a strong variance within the group of Catholic countries that are not explainable by doctrinal but rather structural differences.[8] Secondly, with regard to a bias that could occur regarding other religious traditions, we resort to empirical observation: in all our countries in our sample we find that higher religious attendance of the parents is associated with stronger religious beliefs of the respondents - this also holds for the only Muslim country in our sample (Turkey).

Because we are interested in the overall effect of the family, we average mother's and father's religious attendance. If data were available for only one parent, we used that. Mother's and father's religious attendance are highly correlated $(r=.78$ in the pooled sample), and have similar correlations with other variables (results available on request). Parents' religious attendance is recoded according to the following scale:

Secular (1) Parents never attend religious services;

(2) Parents attend about once a year;

(3) Parents attend several times a year up to once a month;

(4) Parents attend several times a month up to almost every week; and

Devout (5) Parents attend every week or more often.

\section{Denomination that the respondent was raised in}

In order to account for the differences in religious beliefs that exist between different religious traditions, we include a measure of the religious tradition that the respondent has been raised in. This information is available for almost every country in the sample, with the exception of Ireland and Poland 1991. We followed Smith et al.'s example (Smith, Sawkins, and Seaman 1998) and used the denomination of the mother in these cases. We used a simplified categorization of the respondent's religious denomination that comprises 6 
categories: 1 - Catholic, 2 - Protestant, 3 - Orthodox Christian, 4 - Muslim, 5 - other, 6 none. The denomination information is included as a dummy variable for each category.

\section{National religiosity}

We measure the religious environment at the time of the respondent's upbringing in the same fashion as Kelley and de Graaf (1997). Thus we take the religiosity of other people in a nation as an indicator for the density of religious networks that determines individuals' chances to meet religious or secular friends, teachers and spouses. Our measure is an unweighted average of the parental religious attendance in the nation as a whole.[9] The scale can therefore be interpreted analogously to the individual level measurement of parental religious attendance.

\section{Socialist history}

In order to take the anti-religious policies that all of the ex-socialist countries have experienced into account, we include a dummy variable coded 1 for formerly communist nations and 0 otherwise.

\section{Economic development}

In order to test the effects of modernization and economic development on religious socialization, we measure a nation's level of development by its gross domestic product per capita (GDP p.c.) in 1987 (for the 1991 wave), 1994 and 2004 (for the 1998 and 2008 waves respectively), at parity purchasing power (World Bank 2007). We divided the raw measurement by 1000 in order to make the interpretation of the models easier.

\section{Income inequality}

Another crucial contextual variable is the level of income inequality in a country as measured by the Gini Index. It is an indicator of "existential security" and measures also the incentive that exists for people to make use of different forms of relational social capital. Scores range from 0 (absolute equality) to 1 (absolute inequality).[10] We are using Gini data from Solt's SWIID database (Solt 2009a, 2009b). Based on information from the UN World Income 
Inequality Database (UNU WIDER 2008) Solt created measurements for gross and net income inequality for a wide range of countries and time points using missing data algorithms. The information on net income inequality (after taxes and benefits) is used in this study to account for welfare state redistribution. We entered the respective degree of income inequality for a country in a given survey year (1991, 1998, 2008).

\section{Individual level controls}

As individual level controls we include respondent's age, sex and education level in order to account for composition effects in these characteristics. Education is measured in years of schooling as supplied in the ISSP data.[11] The descriptive statistics of the variables used are shown in Table A-2.2 (Appendix II). Note that all continuous variables have been centred around their grand mean in order to facilitate interpretation (Snijders and Bosker 2011).

\section{Method and analytical strategy}

We use multilevel analysis for all the tests of our hypotheses (Rabe-Hesketh and Skrondal 2005; Snijders and Bosker 2011). The major advantage of multilevel analysis in this case is the capability to model the unexplained variance in levels of religious beliefs as well as in the effect of parents' religious attendance across societies. Therefore we introduce a random slope for parents' religious attendance. The goal of our modeling exercise is to identify the cross-level interaction terms that minimize the variance in the slopes of the parental religious attendance effect; the differences in efforts that parents have to undertake in order to inculcate religious beliefs in their children will then be explained by the contextual differences between the countries. Positive signs of the parental religious attendance interaction terms indicate that a certain context increases the impact of parents on childrens' religious beliefs; negative signs show that a certain context decreases their impact.

In total we estimated 10 different multilevel models with individuals nested in countries and countries cross-nested in survey-years. By this we are controlling for period 
effects on religious beliefs; it is assumed that the same country can be present in several survey years. In all models that we will discuss, all metric variables have been centred around their grand mean.[12] The reported standard errors of the estimates are corrected for the clustering within countries (Huber-White Sandwich estimators).[13] The first model is a 'null model' which serves as a benchmark to assess the existing variance between individuals, countries and survey-years.

After this we fitted an 'individual-level variables' model, which contains all individual-level controls (sex, age and age ${ }^{2}$, education, religious denomination raised in) and the amount of religious socialization received (parents' religious attendance). The effect of parents' religious attendance is allowed to vary between countries, which is key in the modeling exercise. This model serves as a benchmark to asses how much of the variance in religious beliefs between individuals and countries can be explained by individual characteristics and countries' varying composition thereof. From this model we predicted 'Empirical Bayes estimates'. These estimates can be interpreted as the country-level residuals regarding the levels of religious beliefs (random intercepts) and the slopes of the religious socialization variable (random slopes) after controlling for all individual characteristics (Snijders and Bosker 2011). In a first step we inspect these residuals visually in order to get a first impression of the explanatory power of the contextual variables and in order to identify potential outliers (see following section).

The next step involved running a series of models that contain the cross-level interaction terms of parents' religious attendance and the country-level characteristics (national religiosity, ex-socialist country, GDP, Gini). We tested each interaction effect first without control of the national religiosity interaction and then under control of it. This is a way to find out if the observed effects are confounded with national religiosity. 
In a last step we estimated a model that includes all interaction terms in order to check which contextual characteristic has the strongest effect under control of all other moderating variables. All models contain all country level and individual level controls. However, in order to keep the presentation of the results as short and simple as possible, we only report the country-level results and the cross-level interaction terms in Table 2. The full results, including all individual-level estimates, can be found in Appendix III. The goodness-of-fit indicators and variance components for all models are included in the appendix as well (Table A-3.3). Table A-2.2 in Appendix II shows the descriptive statistics of our sample.

\section{Results}

\subsection{Bivariate results}

Figure 1 illustrates the cross-country variation of the socialization effect on religious beliefs for the countries in our sample (averaged over all three survey waves). We predicted the country-level residuals (Empirical Bayes estimates) from the 'individual-level variables model' and added them to the fixed effect of parents' religious attendance $(\beta=6.35, \mathrm{p} \leq .001$; see full model results in the appendix).[14] These are the 'country-specific socialization effects'.

\section{-FIGURE 1 ABOUT HERE-}

Countries in which we actually observe 'average' socialization effects are Great Britain and Australia, but also, somewhat surprisingly, countries like Italy and Poland. We would expect socialization effects to be considerably lower here, given the large and strongly religious parental generations in these countries. In the lower range of socialization effects (effect sizes between 0 and 5) we find most Latin American societies, but also Portugal and the USA. Religious socialization in these societies could be characterized as fairly easy to implement, 
because individuals are religious independently of the amount of socialization received from their parents. And, finally, the countries that show the highest parental socialization effects are the Scandinavian and former socialist countries (Finland, Norway, Slovakia, Sweden).[15] Each point increase in parents' religious attendance increases indívidual religious beliefs by 10 to 12 points. Religious socialization in these societies can be considered to be fairly costly because individuals' religious beliefs depend strongly on their parents' religiosity.

\section{-FIGURE 2 ABOUT HERE-}

Figure 2 allows us to investigate the country-specific socialization effects further. We plotted the effects against our country level context variables, levels of national religiosity, GDP per capita, and the Gini-Index.

Looking at national religiosity, we find some evidence that confirms Kelley and de Graaf's original finding $(H 1)$. Countries with overall high levels of religiosity (in the parental generation) show smaller religious socialization effects. However, we find that Poland and Ireland, the two European countries with the most religious parental generations, exhibit very high socialization effects. In contrast to that we find that Russia, where the national religious context was very weak due to its communist legacy, has smaller socialization effects than expected. (This also holds for Bulgaria, Latvia and Ukraine.) The national religious context seems to play a role in moderating religious socialization, yet the outlying cases weaken its explanatory power.

Regarding the effect of economic development (H3), we find the expected increase of socialization effects with higher levels of GDP. Yet this relationship is far from perfect as well. Most former socialist countries indeed show higher socialization effects than what we would expect from their modernization levels alone. This is in line with $H 2$, which predicted higher socialization costs due to anti-religious policies during the communist era. 
But the strongest outlying case in respect to GDP is the US. We find very low socialization effects despite its high economic development.

Lastly, the effects of inequality on religious socialization effects seem to be remarkably strong $(H 4)$. The correlation between country-specific socialization effects and the Gini coefficient is $r=-.86$. Thus we observe the strongest socialization effects in the fairly equal Scandinavian societies and smallest socialization effects in unequal Latin America and South Africa. Ireland, Poland, Russia and the US do not seem to be outliers anymore; their socialization effects seem to be well in line with their levels of inequality.[16] We can conclude from this visual inspection of the country-specific socialization effects that neither national religiosity nor GDP are main drivers behind effective religious socialization - it is inequality. These results will be put under further scrutiny in our multivariate analysis.

\subsection{Multivariate results}

The results of our modelling exercise can be found in Table 2. However, while all models include country-level and individual-level control variables, we only present the coefficients that are essential in the interpretation of the cross-level interactions between context variables and parents' religious attendance.[17] The detailed model results, tables containing standardized model coefficients, and information on variance components and goodness of fit measures can be found in Appendix III (Tables A-3.1 to A-3.3).

Table 2 is organized as follows. The first set of results ('Context interaction only') shows the coefficients from the models in which only the cross-level interaction term between the context variable in question and parents' religious attendance was included. (However, all other country-level and individual-level variables are included as main effects.) Thus the coefficient in the 'National religiosity' column $(\beta=-1.81 ; \mathrm{p} \leq .05)$ is the interaction effect 'National religiosity $X$ parents' religious attendance'. The coefficient $\beta=2.12$ (n.s.) is the main effect of national religiosity on religious beliefs when parents' religious attendance takes 
the value 0. (Since all our continouus variables are centred around the grand-mean this implies the average score in the sample.) The coefficient for parents' religious attendance indicates the effect when the contextual variable takes the value 0.[18]

In the second set of models ('Context interaction + Nat. rel. IA'), we included the interaction term of the contextual variable in question, but also added the Nat. rel. X parents' rel. att. interaction to the model.[19] Thus we are estimating the effect of the context variables on religious socialization effects under control of national religiosity. In the last model specification ('Context interaction + all other IA') we included the interaction terms between all contextual variables and parents' religious attendance in the model. This means we are estimating the context effect on religious socialization while controlling for all other contextual factors. Whenever we use the formulation "main effect" for the contextual characteristics, this has to be understood as applying to respondents with average levels of religious socialization (parents attended religious services several times a year). We will refine his interpretation further by plotting marginal effects of the interaction variables (see Figures 3 and 4).[20]

\section{-TABLE 2 ABOUT HERE-}

Our results show that we can confirm hypotheses $H 1, H 2$ and $H 4$ according to the 'Context interaction only' models. Kelley and de Graaf's original finding that parents have to invest less into the religious upbringing of their children when the national religious context is strong, is confirmed by the first model $(\beta=-1.81 ; p \leq .05)$. However, there is no significant main effect of national religiosity on individual religious beliefs $(\beta=2.12$; n.s.).[21] One caveat in regard to the interpretation of the interaction effects should be highlighted. Any interaction effect must be interpreted in light of the values of the variables from which the interaction is created (Brambor, Clark, and Golder 2006; Berry, Golder, and Milton 2012). The marginal effect of our contextual variables is not constant across the range of individuals' 
levels of religious socialization. Furthermore, the effects can be interpreted symmetrically. National religiosity might influence the effect of religious socialization by increasing or decreasing socialization costs. But it would be equally valid to interpret individual religious socialization as influencing the effect of national religiosity on religious beliefs. All our hypotheses are formulated in a way that favors the former interpretation (context conditions socialization). In order to facilitate interpretation, we plotted the marginal effects of the interacting variables in our models in Figures 3 and 4.[22] Figure 3 can be used to evaluate whether the first interpretation is valid (context conditions socialization); Figure 4 illustrates whether the second interpretation (socialization conditions contextual effects) makes more sense. From Figure 3 (top left graph) follows that the marginal effect of parents' religious attendance is conditioned by levels of national religiosity. The higher levels of religiosity in a country, the smaller the marginal effect of religious socialization on religious beliefs (the confidence interval overlaps with 0 at very high levels of national religiosity). The symmetrical interpretation is plotted in Figure 4 (top left graph). Here we find that national religiosity only exerts a marginal effect different from 0 for respondents with low levels of religious socialization (parents' religious attendance scores 1 or 2), as the confidence interval does not overlap here. Levels of national religiosity do not raise religious beliefs for the whole population, but only for the weakly socialized. (A one point increase in national religiosity is estimated to increase religious beliefs by approximately 5 points for those with a weak religious background.) Substantially, the first interpretation makes more sense, since weakly socialized individuals are less likely to be found in overall strongly religious societies.

Investigating the results further, we find the expected positive interaction effect for ex-socialist societies, indicating that socialization costs were indeed increased through the introduction of anti-religious policies during the communist era $(\beta=1.89 ; \mathrm{p} \leq .05)$. However, looking at the marginal effect plots, we have to conclude that our interpretation of formerly 
socialialist societies conditioning socialization effects cannot be upheld. From Figure 3 (top right graph) we can see that the marginal effects of religious socialization are approximately identical in non-socialist and ex-socialist societies alike (overlap of confidence intervals). The interpretation that growing up in a formerly socialist country has different effects for persons with different levels of religious socialization makes more sense (Figure 4, top right graph). We find that the effect of the ex-socialist dummy is negative and significant for those with parents that attended religious services less than several times a year ( $=3$ points). This interpretation fits with the observation that the interaction effect vanishes after the introduction of the national religiosity interaction. A plausible interpretation is that antireligious policies depressed overall religiosity levels in socialist societies, thereby raising socialization costs.[23]

Our evidence does not support hypothesis H3. In none of the models that we estimated did we find a significant positive interaction between GDP and parents' religious attendance. All results in Table 2 show that the interaction term is basically 0 . It is true that economic development seems to be negatively related to religious beliefs; this is shown by the significant negative main effect of GDP $(\beta=-.20 /-.20 /-.23 ; p \leq .001)$. However, contrary to our expectation, the effort that parents have to undertake in order to socialize their children into a religious worldview are unrelated to levels of economic development. The marginal effect plots confirm this finding. The marginal effect of religious socialization is constant over all levels of GDP, and changes in GDP affect persons with different socialization backgrounds equally.

\section{-FIGURE 3 ABOUT HERE-}

The most interesting and strongest effects are found regarding levels of inequality (H4). In line with the simple analysis of the country-specific socialization effects in the last section, we find a strong, negative interaction effect of income inequality and parents' 
religious attendance on religious beliefs. Moreover, this effect remains stable, no matter which other interaction terms we include. In all three model formulations we observe an effect of roughly $\beta=-.30(p \leq .001)$. In addition to the interaction effect we also observe a strong main effect of inequality on religious beliefs $(\beta=.80 ; p \leq .001)$. These results suggest that income inequality is a strong driver behind religious beliefs and that people born into an unequal context will aqcuire religious beliefs easily, while their parents' religiosity does not matter strongly in this regard. The marginal effect plots support this interpretation. We observe that increases in inequality decrease the marginal effect of religious upbringing strongly (Figure 3). The second interpretation is also valid: increases in inequality affect those from weaker socialization backgrounds stronger than those from strongly religious backgrounds (Figure 4).

\section{-FIGURE 4 ABOUT HERE-}

The effect of inequality is further illustrated in Figure 5. Based on the 'Gini interaction only' model, the plot shows predicted levels of religious beliefs for a male person, raised as a Catholic of average age and education level in a non ex-socialist society. We allow for different levels of individual religious socialization and predict religious beliefs for this person living in a low $($ Gini $=25)$, average $($ Gini $=35)$ and high inequality society $($ Gini $=50)$.

\section{-FIGURE 5 ABOUT HERE-}

While we find a fairly strong impact of religious socialization in the low and average condition, it does not matter for religious beliefs in the high-inequality condition. Persons with parents that rarely or never attended religious services are almost equally religious as persons from highly religious backgrounds.

Furthermore, the effect of inequality persists independently from the overall religiosity of a nation. This suggests that inequality does not just lead to high levels of religiosity, which in turn affects the pool of ineraction partners that people can choose from. 
The effect seems to work through a separate mechanism. Due to space restrictions, we cannot examine the possible mechanism in greater detail here. However from all possible explanations that we discussed before (existential security, political legitimization, social capital), the existential security explanation seems least plausible. If this explanation would be true, we should also find a positive interaction effect of GDP.[24] We suggest to further explore the underlying mechanism of the inequality effect in greater detail in future research.

An evaluation of the changes in variance components and the goodness of-fitmeasures showed that our modeling exercise was successful (the detailed information can be found in Table A3-3.3, Appendix III). Our goal was to explain variation in the effects of parents' religious attendance on religious beliefs through the introduction of cross-level interactions between context variables and the individual level socialization indicator. While most of the various context variables decrease the variance in random slopes (with exception of the GDP interaction), the strongest decrease is obtained through the introduction of inequality as an explanatory variable. Adding more interaction effects to our model ('Context interaction + all other IA') increases the explanatory power slightly, but the BIC suggests that the 'Gini IA only' model provides the most parsimonious fit to the data.

\section{Conclusion}

The aim of this paper was to examine, which societies are able to provide a strong context of religious socialization outside of the family. Therefore we started from Kelley and de Graaf's (1997) original argument that levels of religious beliefs in the parental generation exert a significant and independent effect on individuals' religious beliefs and help to reduce the effect of parental socialization. We were able to confirm this original finding, however several outlying observations weakened the power of their explanation. Countries like Ireland and Poland, which indeed show high levels of overall religiosity, were found to have unexpectedly high parental socialization effects. This is not in line with Kelley and de Graaf's original 
explanation. Inspired by Berger's (1969) notion of the "sacred canopy" we asked, under which conditions this sacred canopy can be maintained most easily. We offered an interpretation of country-specific socialization effects, which maintains that religious beliefs are transmitted most effectively when the influence of parents' religiosity is minimized. Under this condition societies exert a socialising effect on their own in such a way that even weakly socialized individuals adopt strong religious beliefs.

In addition to Kelley and de Graaf's (1997) original hypothesis we derived three hypotheses about how religious socialization should be affected by various societal contexts. We expected increased effects of parental socialization in formerly socialist countries, where anti-religious policies prevented religious socialization through the larger societal context. Based on classical secularization theory and Norris and Inglehart's existential security hypothesis we predicted that increases in economic development should lead to religious beliefs being more dependent on parents' efforts. Drawing on previous findings and arguments adopted from political economy and social capital research, we hypothesized that income inequality should decrease the impact of parents' religiosity on individuals' religious beliefs.

Effects of parental religiosity on individual religious beliefs were found to interact with the upbringing in ex-socialist societies. Religious beliefs were found to decrease more strongly under socialist upbringing for those with a weaker religious socialization. The interaction effect vanished after controlling for levels of national religiosity, which suggests that socialist countries suppressed religious practice in general, thereby leading to less religious socialization through the family.

No effect was observed for economic development. Parents' religiosity matters as much for religious beliefs in rich as in poor nations. This result casts doubt on a simple explanation of socialization effects along the lines of the existential security hypothesis. 
Moreover, this means that economic development does not seem to be a main driver behind increases in socialization costs.

It turned out that income inequality has the strongest impact on religious socialization effects. In very unequal societies those with weakly religious parents are as religious as those with strongly religious parents. This finding was robust even after controlling for levels of national religiosity and all other contextual factors. Increases in the costs of religious socialization therefore do not occur because societies develop economically. Socialization becomes more costly when societies reduce income inequality. The country-specific socialization effects of almost all country cases that were outliers in regard to their levels of religiosity (Ireland, Poland), their socialist history (Russia) or their economic development (USA) could be explained very well when their levels of inequality were acccounted for.

However, we are not able to provide more than a tentative explanation for these strong inequality effects. From all possible explanations discussed here, we think that a social capital explanation seems to be most plausible. As long as inequality is high, people have an incentive to invest in relational social capital that might be provided by religious organizations. Moreover, the signalling of trustworthiness or religious conformity might prove more important when access to useful ressources is distributed very unequally across society.

The results discovered allow for a variety of future research directions. Besides extra tests with more more longitudinal data in order to test more robustly the effects of contextual changes within countries, we suggest exploring possible mechanisms behind the effect of inequality in more detail in future research.An important question to be answered is whether inequality rather is a source of insecurity that perpetuates the demand for religion as a coping resource or whether religion should be seen as a source of social capital that proves particularly valuable under unequal conditions. Further improvements should also be made in 
order to establish a causal effect of inequality, as endogeneity still poses a problem to our findings. It is possible that inequality is created or maintained in societies where religious beliefs represent a widely shared norm (see also Solt, Habel, and Grant 2011). And lastly, cohort analyses that account for changes in inequality would complete our picture about the processes that drive religious change. 


\section{References}

Arbuckle, James L. 2007. Amos (Version 18) [Computer Programme]. Chicago: SPSS.

Beit-Hallahmi, Benjamin and Michael Argyle. 1997. The psychology of religious behaviour, Belief and experience. London, New York: Routledge.

Bengtson, Vern L., Casey E. Copen, Norella M. Putney, and Merril Silverstein. 2009. A longitudinal study of the intergenerational transmission of religion. International Sociology 24:325-345.

Benson, Peter L., Michael J. Donahue, and Joseph A. Erickson. 1989. Adolescence and religion. Research in the Social Scientific Study of Religion 1:153-181.

Berger, Peter L. 1969. The sacred canopy - Elements of a sociological theory of religion. New York: Anchor Books.

Berger, Peter L. and Thomas Luckmann. 1966. Secularization and pluralism. International Yearbook for the Sociology of Religion 2:73-84.

—. 1969. Die gesellschaftliche Konstruktion der Wirklichkeit. Frankfurt/Main: Fischer.

Berry, William D., Matt Golder, and Daniel Milton. 2012. Improving tests of theories positing interaction. Journal of Politics 74(3):653-671.

Billiet, Jacques. 2003. Cross-cultural equivalence with structural equation modeling. In Cross-Cultural Survey Methods, edited by Janet Harkness, Fons van de Vijver, and Peter Mohler, pp. 247-265. New York: Wiley.

Bisin, Alberto and Thierry Verdier. 2000. Beyond the melting pot: Cultural transmission, marriage, and the evolution of ethnic and religious traits. The Quarterly Journal of Economics 115:955-988.

Bjørnskov, Christian. 2007. Determinants of generalized trust: A cross-country comparison. Public Choice 130:1-21. 
Borowik, Irena. 1997. Introduction. Religion in post-Communist societies. In New religious phenomena in Central and Eastern Europe, edited by Irena Borowik and Grzegorz Babinski, pp. 7-24. Krakow: Nomos.

Brambor, Thomas, William R. Clark, and Matt Golder. 2006. Understanding interaction models: Improving empirical analyses. Political Analysis 14:63-82.

Brown, Timothy A. 2006. Confirmatory factor analysis for applied research. New York: Guilford Press.

Bruce, Steve. 2002. God is dead-Secularization in the West. Oxford: Blackwell Publishers.

—. 2003. Politics and religion. Cambridge: Polity Press.

Byrne, Barbara M., Richard J. Shavelson, and Bengt Muthén. 1989. Testing for the equivalence of factor covariance and mean structures: The issue of partial measurement invariance. Psychological Bulletin 105:456-466.

Chen, Fang Fang. 2007. Sensitivity of goodness of fit indexes to lack of measurement invariance. Structural Equation Modeling 14:464-504.

Davidov, Eldad, Peter Schmidt, and Jacques Billiet (Eds.). 2010. Methods and applications in cross-cultural analysis. New Jersey: Routledge.

Finke, Roger and Amy Adamczyk. 2008. Cross-national moral beliefs: The influence of national religious context." Sociological Quarterly 49:617-652.

Firebaugh, Glenn and Brian Harley. 1991. Trends in United States church attendance Secularization and revival, or merely life-cycle effects. Journal for the Scientific Study of Religion 30:487-500.

Francis, Leslie J. and Laurence B. Brown. 1991. The influence of home, church and school on prayer among 16-year-old adolescents in England. Review of Religious Research $33: 112-122$. 
Froese, Paul 2004. Forced secularization in Soviet Russia: Why an atheistic monopoly failed. Journal for the Scientific Study of Religion 43:35-50.

Gill, Anthony and Erik Lundsgaarde. 2004. State welfare spending and religiosity - A crossnational analysis. Rationality and Society 16:399-436.

Glaeser, Edward L., Giacomo A. M. Ponzetto, and Jesse M. Shapiro. 2005. Strategic extremism: Why Republicans and Democrats divide on religious values. Quarterly Journal of Economics 120:1283-1330.

Gruber, Jonathan. 2004. Pay or pray? The impact of charitable subsidies on religious attendance. Journal of Public Economics 88:2635-2655.

Hancock, Gregory R. 2006. Power analysis in covariance structure models. In Structural equation modeling: A second course, edited by Gregory R. Hancock and Ralph O. Mueller. Greenwood, CT: Information Age Publishing, Inc.

Huber, John D. and Piero Stanig. 2007. Redistribution through taxes and charity: The cost of "Compassionate Conservatism" to the secular poor. Previously unpublished working paper http://www.columbia.edu/ ps2025/HuberStanigAPSA2007.pdf.

Hungerman, Daniel M. 2005. Are church and state substitutes? Evidence from the 1996 welfare reform. Journal of Public Economics 89:2245-2267.

ISSP Research Group. 1991. International Social Survey Programme 1991: Religion I (ISSP 1991). ZA2150. Cologne: GESIS.

—. 1998. International Social Survey Programme 1998: Religion II (ISSP 1998). ZA3190. Cologne: GESIS.

-. 2008. International Social Survey Programme 2008: Religion (ISSP 2008). ZA4950. Cologne: GESIS

Kelley, Jonathan and Nan Dirk. de Graaf. 1997. National context, parental socialization, and religious belief: Results from 15 nations. American Sociological Review 62:639-659. 
Lazerwitz, Bernard and Ephraim Tabory. 2002. National religious context and familial religiosity within a Jewish framework. Review of Religious Research 44:22-37.

Martin, David. 2005. On secularization - Towards a general revised theory. Aldershot: Ashgate.

Maselko, Joanna, Cacey Hughes, and Rose Cheney. 2011. Religious social capital: Its measurement and utility in the study of the social determinants of health. Social Science \& Medicine 73:759-767.

Meredith, William. 1993. Measurement invariance, factor analysis and factorial invariance. Psychometrika 58:525-543.

Meulemann, Heiner. 2004. Enforced secularization - spontaneous revival?: Religious belief, unbelief, uncertainty and indifference in east and West European countries 1991-1998. European Sociological Review 20:47-61.

Müller, Tim. 2009. Religiosity and attitudes towards the involvement of religious leaders in politics. A multilevel analysis of 55 countries.” World Values Research 2:1-29.

Müller, Tim and Anja Neundorf. 2012. The role of the state in the repression and revival of religiosity in Central Eastern Europe. Social Forces 91(2):559-582.

Muthén, Bengt. 1994. Multilevel covariance structure analysis. Sociological Methods \& Research 22:376-398.

Myers, Scott M. 1996. An interactive model of religiosity inheritance: The importance of family context. American Sociological Review 61:858-866.

Nielsen, Niels. 1991. Revolution in Eastern Europe: The religious roots. Orbis: Maryknoll.

Norris, Pippa and Ronald Inglehart. 2004. Sacred and secular - Religion and politics worldwide. Cambridge: Cambridge University Press. 
Rabe-Hesketh, Sophia and Anders Skrondal. 2005. Multilevel and longitudinal modelling using Stata. College Station: Stata Press.

Rose, Richard. 2000. Getting things done in an antimodern society: social capital networks in Russia. In Social capital. A multifaceted perspective, edited by Partha Dasgupta and Ismail Serageldin, pp. 147-171. Washington D.C.: The World Bank.

Ruiter, Stijn and Nan Dirk de Graaf. 2006. National context, religiosity, and volunteering: Results from 53 countries. American Sociological Review 71:191 -210.

-. 2010. National religious context and volunteering: More rigorous tests supporting the association. American Sociological Review 75:179-184.

Ruiter, Stijn and Frank van Tubergen. 2009. Religious attendance in cross-national perspective: A multilevel analysis of 60 countries. American Journal of Sociology 115:863-895.

Sacerdote, Bruce and Edward L. Glaeser. 2001. Education and religion. NBER Working Paper Series - http://www.nber.org/papers/w8080.

Scheepers, Peer, Manfred T. Grotenhuis, and Frans Van Der Slik. 2002. Education, religiosity and moral attitudes: Explaining cross-national effect differences. Sociology of Religion 63:157-176.

Scheve, Kenneth and David Stasavage. 2006a. The political economy of religion and social insurance in the United States, 1910-1939. Studies in American Political Development 20:132-159.

-. 2006b. Religion and preferences for social insurance. Quarterly Journal of Political Science 1:255-286.

Schwadel, Phillip. 2010. Age, period, and cohort effects on U.S. religious service attendance: The declining impact of sex, southern residence, and Catholic affiliation. Sociology of Religion 71:2 -24. 
Smith, Ian, John W. Sawkins, and Paul T. Seaman. 1998. The economics of religious participation: A Cross-country study." Kyklos 51:25-44.

Snijders, Tom A.B. and Roel J. Bosker. 2011. Multilevel analysis: An introduction to basic and advanced multilevel modeling, 2nd Ed. London: Sage.

Solt, Frederick 2009a. Standardized World Income Inequality Database (SWIID). vol. 2010: http://www.siuc.edu/ fsolt/.

-. 2009b. Standardizing the World Income Inequality Database. Social Science Quarterly 90:231-242.

Solt, Frederick, Philip Habel, and J. Tobin Grant. 2011. Economic ilnequality, relative power, and religiosity. Social Science Quarterly 92:447-465.

Steinmetz, Holger. 2010. Estimation and comparison of latent means across cultures. In Methods and applications in cross-cultural analysis, edited by Eldad Davidov, Peter Schmidt, and Jacques Billiet. New Jersey: Routledge.

Stroope, Samuel. 2011. How culture shapes community: Bible belief, theological unity, and a sense of belonging in religious congregations. Sociological Quarterly 52:568-592.

Tomka, Miklòs. 1994. The sociology of religion in Eastern and Central Europe: Problems of teaching and research after the break-down of Communism. Social Compass 41:379392.

Traunmüller, Richard. 2009. Religion and social integration. Berliner Journal für Soziologie 19:435-468.

Tubergen, Frank van, Manfred te Grotenhuis, and Wout Ultee. 2005. Denomination, religious context, and suicide: Neo-Durkheimian multilevel explanations tested with individual and contextual data. American Journal of Sociology 111:797-823.

UNU WIDER. 2008. World Income Inequality Database, Version 2.0c, May 2008. vol. 2010: http://www.wider.unu.edu/research/Database/en GB/wiid/. 
Uslaner, Eric M. and Mitchell Brown. 2005. Inequality, trust, and civic engagement. American Politics Research 33:868-894.

van der Slik, Frans, Nan Dirk de Graaf, and Jan Peters. 1994. Kerkverlating in Nederland. Sociale Wetenschappen 38:23-50.

Vandenberg, Robert J. and Charles E. Lance. 2000. A review and synthesis of the measurement invariance literature: Suggestions, practices, and recommendations for organizational research. Organizational Research Methods 2:4-69.

Voas, David and Stefanie Doebler. 2011. Secularization in Europe: Religious change between and within birth cohorts. Religion and Society in Central and Eastern Europe. 4:3962.

World Bank. 2007. World Development Indicators 2007 (CD-ROM). Washington: World Bank Publishing.

Wuthnow, Robert. 2002. Religious involvement and status-bridging social capital. Journal for the Scientific Study of Religion 41:669-684.

You, Jong-Sung and Sanjeev Khagram. 2005. A comparative study of inequality and corruption. American Sociological Review 70:136-157. 


\section{Footnotes}

[1] The idea that religious parents socialize their children in a religious family context and inculcate religious beliefs in their children is well known and well documented (Beit-Hallahmi and Argyle 1997; Bengtson, Copen, Putney, and Silverstein 2009; Benson, Donahue, and Erickson 1989; Francis and Brown 1991; Myers 1996). Kelley and de Graaf's contribution is to point out the socialization that is happening outside of the family context.

[2] However, Kelley and de Graaf do not assume that secular parents in very devout contexts make efforts to shield their children from religious influences: "We suggest [...] that most secular parents will not strongly object to their children accepting some religious tenets. [...] [P]arents may see little harm in their children becoming religious" (Kelley and de Graaf 1997:642).

[3] We assume that the same factors that are responsible for the positive correlation of inequality and religiosity explain why religious beliefs are aqcuired easily independent from parents' religiosity.

[4] Rose's definition of a social network that is informal in nature is: "face-to-face relationships between a limited number of individuals who know each other and are bound together by friendship, or propinquity." (Rose 2000:149).

[5] See Table A-1.2.1 in the appendix for the included countries.

[6] The only item which had to be omitted in this study but which had been included in Kelley and de Graaf (1997) is the question on the respondent's feeling of closeness to God. It was not asked in the ISSP 1998 and 2008.

[7] We used Principal Component Factor Analysis, Varimax rotation. All respondents with non-missing values on the scale items were included; the analysis was performed with Stata, version 11.

[8] The results are available on request.

[9] Our measurement differs slightly from the original operationalization. It does not include current levels of beliefs in the measurement because we wanted to give stronger emphasis to the socialization context, which depends on religiosity of the parental generation rather than current beliefs.

[10] The Gini Index has also been rescaled here to a range of 0-100.

[11] Unfortunately the education variable was not available for Northern Ireland in 1998 and 2008. The NIR sample from these survey waves is therefore not included.

[12] We can therefore interpret the regression constant as the level of religious beliefs for a male person with average age and educational level in an average, not ex-socialist society that has been raised as a Catholic. 
[13] Without the correction, we would be overconfident of the standard errors of individual level variables, as the size of the clusters and the sampling errors are not taken into account otherwise.

[14] The 'fixed effect' can be considered as the average effect of parents' religious attendance over all countries in the sample. That is: on average, an increase of parents' religious attendance by one point increases religious beliefs by 6.35 points.

[15] The effects observed in East and West Germany are surprisingly similar given the two areas' differing postwar history. A closer examination of individual level regressions showed that the socialization effects seem to be strongly dependent on the belonging to particular birth cohorts. Before the introduction of the age variable, the socialization effects differ strongly, as expected. After controlling for age (as shown in the figure), we observe similar socialization effects.

[16] South Africa (labeled 'ZA') is an outlier regarding its inequality level. It has an estimated Gini of 66 in the SWIID data, which is probably overestimated. However it does not inflate our estimate of the Gini effect. If deleted, the correlation between inequlity and the socialization effects would even be stronger.

[17] We chose this simpler presentation of results because our research question is focused on the cross-level interaction between socialization context and individual sozialization efforts. The interested reader is referred to the detailed model results in Table A3-1 in Appendix III. In general our findings support an erosion of religious beliefs with increases in economic development and education levels and a decrease in inequality. Differences in the strength of religious beliefs between different faiths are mostly due to differences in religious socialization and demographic characteristics. However, Muslim respondents report overall higher levels of beliefs net of all other factors, while those that were raised in no faith report significantly lower beliefs.

[18] Since main effects in interaction models cannot be interpreted on their own, without taking into account the other conditioning variable, we will present marginal effect plots of the interaction effects in order to aid our interpretation (see also Brambor, Clark, and Golder 2006; Berry, Golder, and Milton 2012).

[19] Obviously, there is only one set of results regarding the national religiosity variable.

[20] The marginal effect of an interaction term can formally be expressed by $\frac{d y}{d x}=\beta_{1} x+\beta_{2} x z$. It shows how the effect of $\mathrm{x}$ on $\mathrm{y}$ changes when the values of the conditioning variable $\mathrm{z}$ change.

[21] We also did not find a main effect of national religiosity on religious beliefs when running a model without the interaction term. Based on a re-analysis of the data for each sample wave we conclude that differences between our findings and Kelley and de Graaf's 1997 article have several reasons: differences in sample selection and size, differences in modelling approach and model specification and different operationalizations 
of variables of interest. The original model excluded the outliers Russia, Israel and the Philippines and included a dummy for the special case of the US. In our models these are included together with many more cases for which data did not previously exist. Also the new data file version that was available to us fixed many of the initial data problems encountered by the authors. We suggest a new explanatory variable, inequality, for which data has only recently become available for a large number of cases. The original approach did not account for clustering of cases in countries and therefore produced overly confident parameter estimates. We operationalized national religiosity in a simpler way, as average religious attendance of parents in each country, whereas the 1997 paper included current religious beliefs in this explanatory variable. Lastly, the original models used simpler model specifications that assumed fixed socialization effects across countries, thereby ascribing a larger explanatory power to the national religious context. Our approach allows variation in slopes. We think that our paper does not refute Kelley and de Graaf's earlier findings, but rather refines and expands their original reasoning.

[22] We would like to thank the anonymous reviewers for pointing out the relevant literature and resources to us (Brambor, Clark, and Golder 2006; Berry, Golder, and Milton 2012).

[23] The main effect of the ex-socialist dummy never reaches statistical significance at the 5\% level while controlling for national religiosity. If this effect is left out of the model, it does show up though. This finding supports the interpretation that decreases in individual religiosity and increases in socialisation costs in socialist countries worked via decreasing overall levels of religiosity.

[24] Increases in security (increases in GDP) should make religious socialization more costly, decreases in security (increases in inequality) should make it less costly. 


\section{Tables and Figures}

Table 1: Percentage Distribution of Responses to Questions about Religious Beliefs: Pooled Data for 41 Nations; ISSP 1991, 1998, 2008.

Please indicate which statement below comes closest to expressing what you believe about God. (Degree of Belief)

I don't believe in God.

I don't know whether there is a God and I don't believe there is any way to find out.

920

I don't believe in a personal God, but I do believe in a higher power of some kind

I find myself believing in God some of the time, but not at others.

While I have doubts, I feel that I do believe in God

$\begin{array}{rr}9 & 60 \\ 17 & 80\end{array}$

I know God really exists and I have no doubts about it.

Which best describes your beliefs about God? (Belief Duration)

I don't believe in God now and I never have

I don't believe in God now, but I used to

I believe in God now, but I didn't used to

I believe in God now and I always have

Number of cases

Standardized loading on factor 1

There is a God who concerns Himself with every human being, personally. (Caring God)

Strongly agree

Agree

Neither agree nor disagree

Disagree

Strongly disagree 


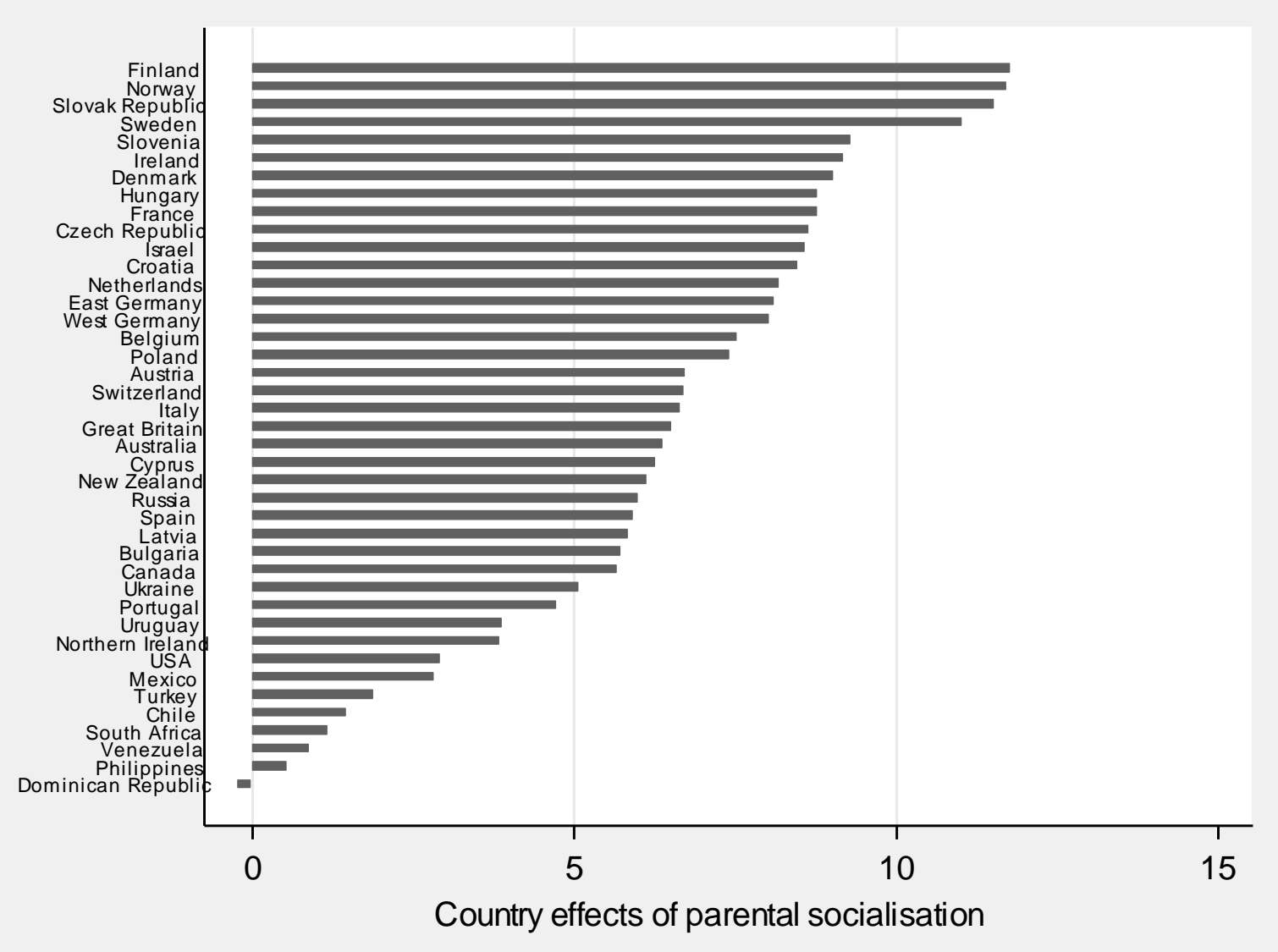

Figure 1: Effects of religious upbringing on religious beliefs in different societies.
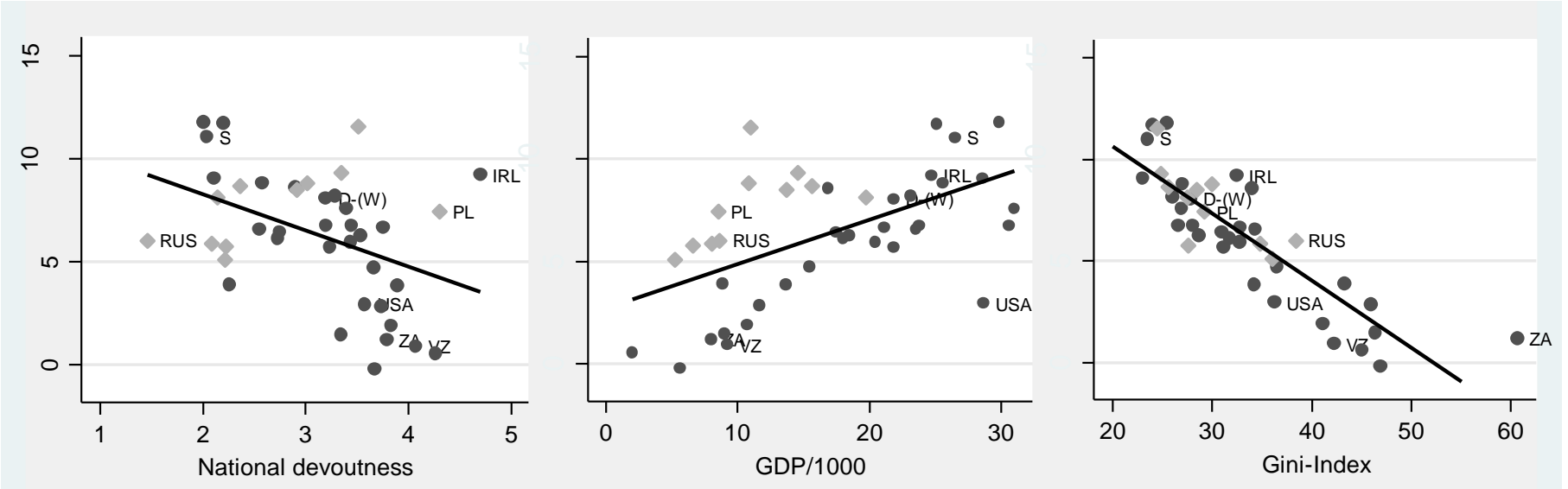

Ex-Socialist $\longrightarrow$ OLS fitted values

Figure 2: Effects of national religiosity, GDP and inequality on country-specific socialization effects. 
Table 2: Context variables and cross-level interaction effects moderating the effects of parents' religious attendance on religious beliefs in 41 societies. Multilevel regression results.

\begin{tabular}{|c|c|c|c|c|c|c|c|c|}
\hline & \multicolumn{2}{|c|}{ National religiosity } & \multicolumn{2}{|c|}{ Ex-Socialist } & \multicolumn{2}{|c|}{ GDP } & \multicolumn{2}{|c|}{ Gini } \\
\hline & Coef. & S.E. & Coef. & S.E. & Coef. & S.E. & Coef. & S.E. \\
\hline \multicolumn{9}{|l|}{ Context interaction only } \\
\hline Interaction term & $-1.81^{*}$ & 0.75 & $1.89 *$ & 0.86 & -0.01 & 0.03 & $-0.30 * * *$ & 0.05 \\
\hline Context main effect & 2.12 & 1.67 & $-5.53^{+}$ & 2.90 & $-0.20 * * *$ & 0.06 & $0.80 * * *$ & 0.10 \\
\hline Parents' religious attendance & $6.42 * * *$ & 0.46 & $5.85 * * *$ & 0.62 & $6.35 * * *$ & 0.51 & $6.50^{* * *}$ & 0.29 \\
\hline \multicolumn{9}{|c|}{ Context interaction + Nat. rel. IA } \\
\hline Interaction term & -- & -- & 1.01 & 1.08 & -0.01 & 0.03 & $-0.29 * * *$ & 0.05 \\
\hline Context main effect & -- & -- & $-5.02^{+}$ & 2.80 & $-0.20 * * *$ & 0.06 & $0.80 * * *$ & 0.10 \\
\hline Parents' religious attendance & -- & -- & $6.14 * * *$ & 0.53 & $6.41 * * *$ & 0.47 & $6.52^{* * *}$ & 0.28 \\
\hline \multicolumn{9}{|c|}{ Context interaction + all other IA } \\
\hline Interaction term & -0.61 & 0.45 & 0.45 & 0.67 & 0.02 & 0.03 & $-0.29 * * *$ & 0.05 \\
\hline Context main effect & 1.78 & 1.53 & $-5.06^{+}$ & 2.74 & $-0.23 * * *$ & 0.05 & $0.80 * * *$ & 0.10 \\
\hline Parents' religious attendance & $6.40 * * *$ & 0.32 & $6.40 * * *$ & 0.32 & $6.40 * * *$ & 0.32 & $6.40 * * *$ & 0.32 \\
\hline
\end{tabular}

Notes: ${ }^{+} p \leq .10 ; * p \leq .05 ; * * p \leq 0.01 ; * * * p \leq .001$, robust SEs, corrected for clustering in countries. All models include controls on country and individual level and a random slope for parents' religious attendance. 'Context interaction only' and 'Context interaction + Nat. Rel. IA' are identical for the national religiosity variable. Full model results in Appendix III, Tables A-3.1 and A-3.2.
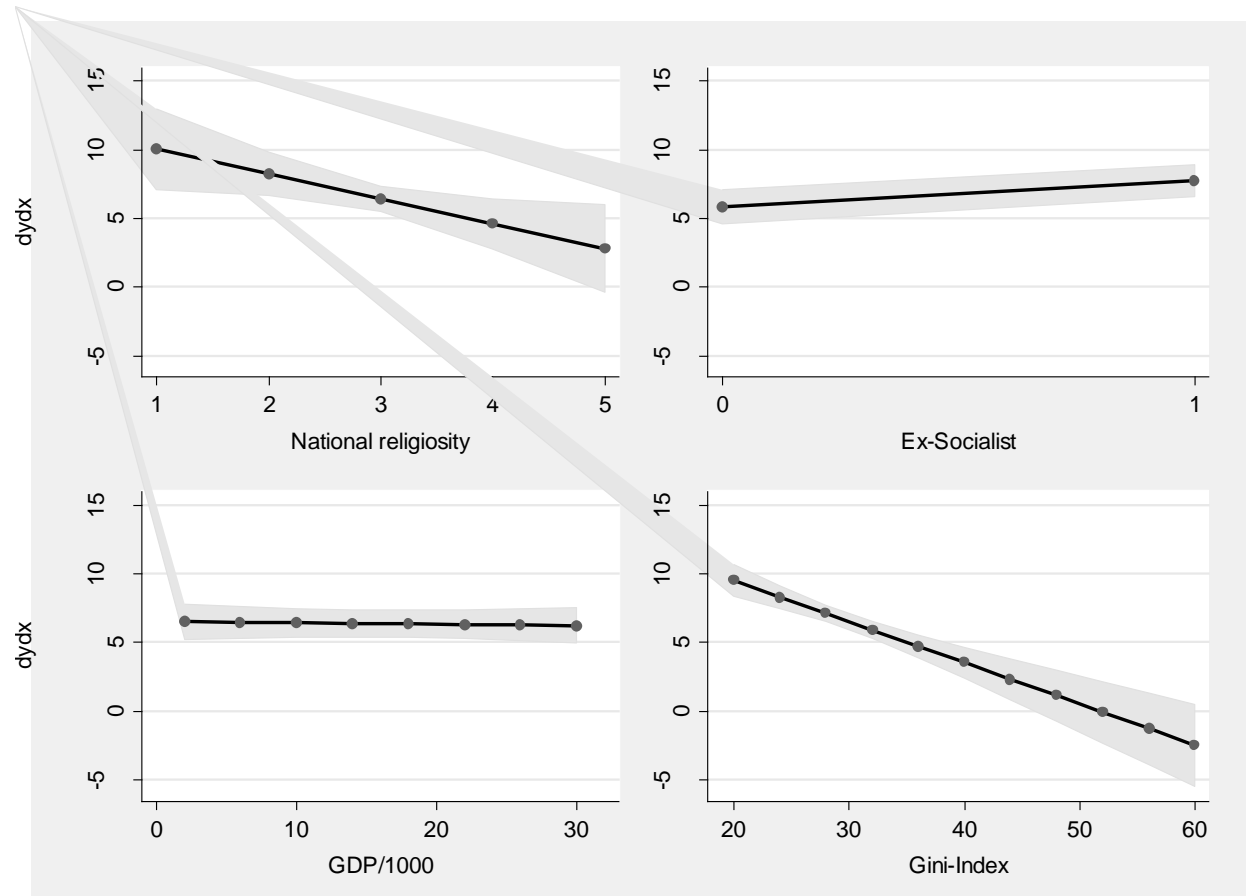

Figure 3: Marginal effects of respondents' religious socialization on individual religous beliefs at different levels of the contextual variables. (Shaded area: $95 \%$ confidence interval.) 


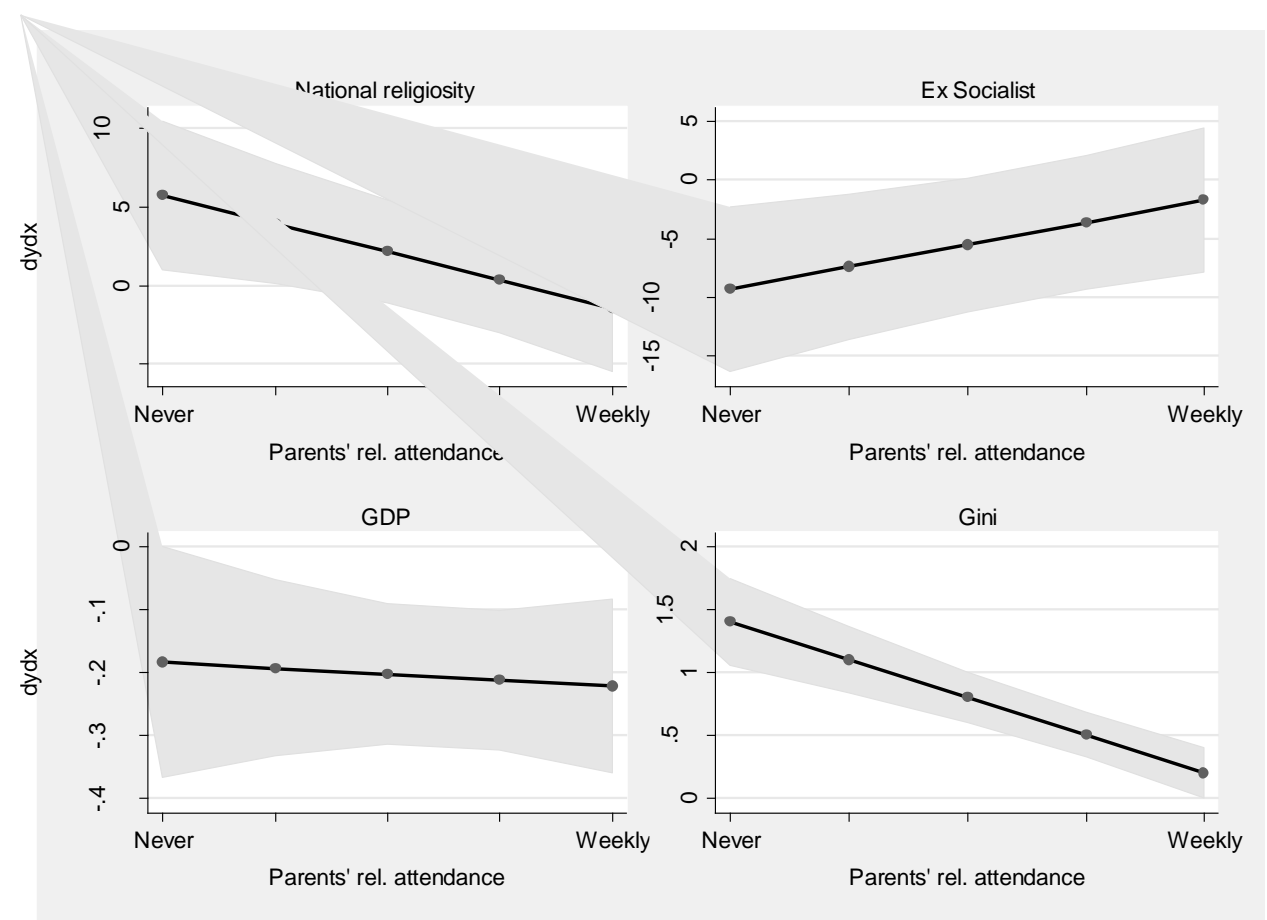

Figure 4: Marginal effects of the contextual variables on individual religous beliefs at different levels of respondents' religious socialization. (Shaded area: 95\% confidence interval.)

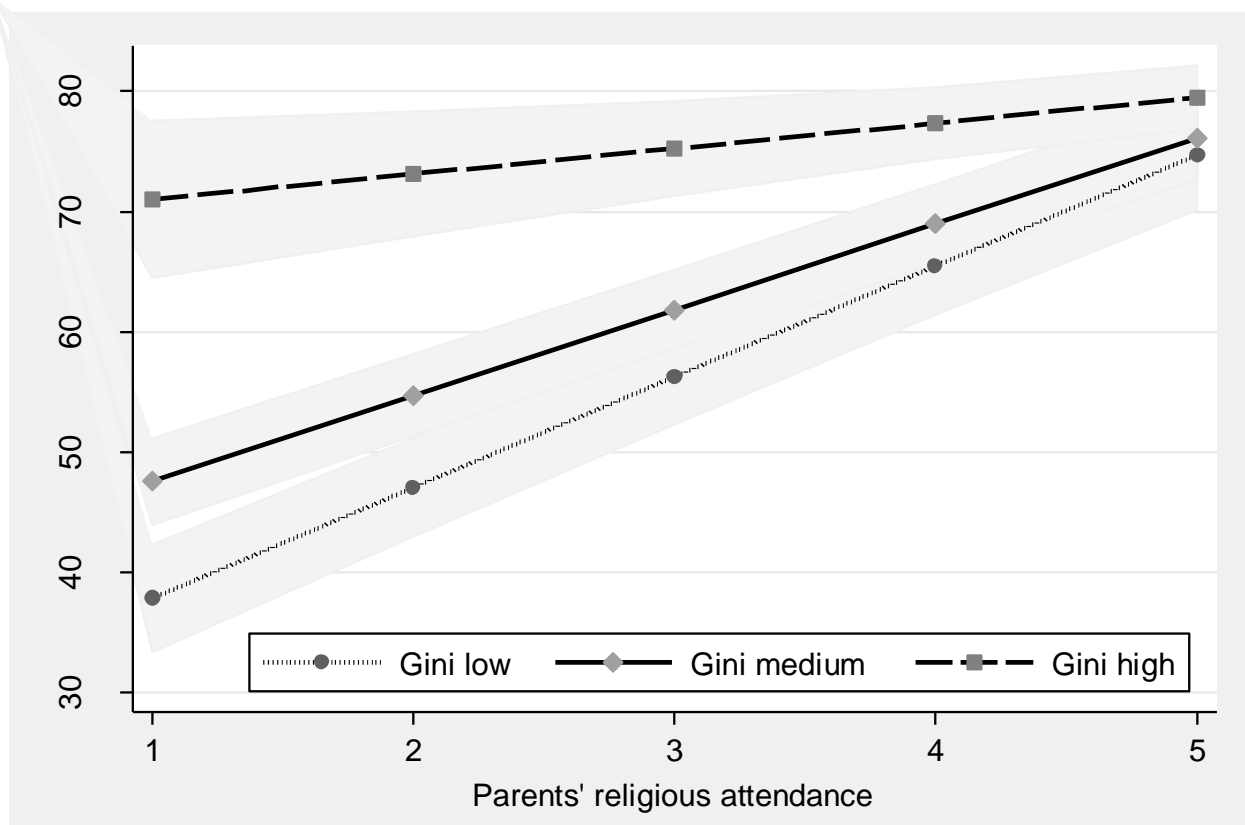

Figure 5: Religious beliefs and religious attendance as a function of individual socialization and income inequality. 


\section{Appendices}

\section{Appendix I -Testing the equivalence of meaning of the religious orthodoxy scale over time and countries}

For our tests of the propositions we have to assure that the equivalence of meaning of the three items for measuring religious belief (Degree of Belief, Belief Duration and Caring God) over all countries and time points is given (Billiet 2003; Davidov, Schmidt, and Billiet 2010; Vandenberg and Lance 2000). In most international comparative multi-level analyses this equivalence of meaning has implicitly been assumed but not tested. If this assumption is not fulfilled, the parameters of the multilevel model may be severely biased (Muthén 1994).

The procedure we use for the test of equivalence of meaning of the three items over time and over countries is a Multiple Group Confirmatory Factor Analysis (MGCFA). We used the programme AMOS version 18 for this purpose (Arbuckle 2007). As the number of countries changed over time (see Table A-2.1) we had to perform 4 multiple group factor analyses with differing number of countries. One multi-group confirmatory factor analysis for the countries involved in 1991 and 1998, one for those taking part in the ISSP in 1991 and 2008, one for the countries participating 1998 and 2008 and one for the countries in 1991, 1998 and 2008. For our purpose we test whether all the factor loadings of each of the items are equal in the four sets of countries just mentioned and over time besides random fluctuations. This type of equivalence - called metric equivalence - gives a necessary but not sufficient condition for the equality of meaning of items over different nations and time points. Furthermore it is a prerequisite for comparing regression coefficients over countries (Meredith 1993; Vandenberg and Lance 2000).

The procedure was performed according to Vandenberg and Lance's suggestion (2000). Firstly we set up an unconstrained model for all countries and time points. This implies that we postulate that the three items are explained in all countries by one factor and 
that these items have no error correlations (configural invariance). In the second step we test for metric invariance, that is whether the loadings are equal beside random fluctuations. Full metric invariance was not fitting the data adequately. Only partial metric invariance was reached as the factor loadings of first two items (Degree of Belief and Belief Duration) were invariant over time and countries, whereas the loading of the third item (Caring God) varied systematically between the countries.

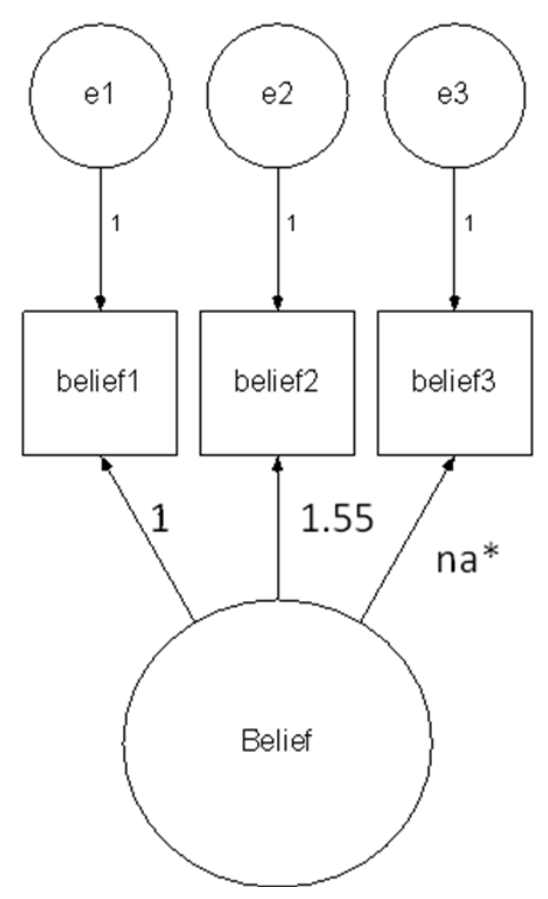

Figure A-1.1: Graphical representation of the performed MGCFA.

Partial invariance is, however, sufficient to establish equal meaning over time and countries (Byrne, Shavelson, and Muthén 1989). Finally, for a small subset of countries, we had to introduce error correlations between the residual of item 1 and the residual of item 3 to get an adequate fit. This was only necessary for USA, Russia and Philippines. At all three time points we observed that in these countries the meaning of the items 1 and 3 were more closely related to each other than in the majority of countries (see Brown 2006: 181-186). Given the large sample size we prefer using the Comparative Fit Index (CFI>0.01) for model selection instead of the chi square difference test (Chen 2007). 
The graphical model with the unstandardised coefficients for all countries taking part in all three points can be found in Figure A-1.1. The Comparative Fit Measures (CFI) and the Aikaike Fit Measures for the saturated and the specified model are given in Table A-1.1. The results show that the CFI values are without exception very good. Values $>.95$ indicate a very good fit of the model. Given these results and taking into account that the factor loadings within countries are rather similar, it is legitimate to use composite scores for this construct in the multi-level analyses presented later (Steinmetz 2010).

Table A-1.1: Fit Measures of the Final Model of the MGCFA (41 countries).

\begin{tabular}{|c|c|c|c|c|c|}
\hline & & \multicolumn{4}{|c|}{ Sample waves } \\
\hline & & $1991-1998$ & $1991-2008$ & $1998-2008$ & $\begin{array}{c}1991-1998- \\
2008\end{array}$ \\
\hline $\begin{array}{l}\text { Comparative } \\
\text { Index }\end{array}$ & Fit & .997 & .998 & .997 & .998 \\
\hline
\end{tabular}

The additional test for scalar invariance showed, that this assumption was falsified. Therefore no mean comparisons for the latent underlying construct 'belief' in the strict sense can be performed. (However, this is not relevant for our paper as were are not interested in mean comparisons but higher order interactions.) 


\section{Appendix II - Countries included in the analyses and summary statistics}

Table A-2.1: Countries included in the sample.

\begin{tabular}{|c|c|c|c|c|}
\hline \multirow[b]{2}{*}{ Country } & \multicolumn{3}{|c|}{ Year of survey } & \multirow[b]{2}{*}{ Total } \\
\hline & 1991 & 1998 & 2008 & \\
\hline AUS-Australia & 2,115 & 1,250 & 0 & 3,365 \\
\hline D-W-Germany-West & 1,312 & 915 & 1,079 & 3,306 \\
\hline D-E-Germany-East & 1,471 & 886 & 480 & 2,837 \\
\hline GB-Great Britain & 1,184 & 758 & 1,878 & 3,820 \\
\hline NIRL-Northern Ireland & 798 & 0 & 0 & 798 \\
\hline USA-United States & 1,287 & 1,187 & 1,342 & 3,816 \\
\hline A-Austria & 977 & 976 & 988 & 2,941 \\
\hline H-Hungary & 985 & 984 & 904 & 2,873 \\
\hline I-Italy & 901 & 889 & 1,009 & 2,799 \\
\hline IRL-Ireland & 1,002 & 895 & 1,859 & 3,756 \\
\hline NL-Netherlands & 1,590 & 1,830 & 1,797 & 5,217 \\
\hline N-Norway & 1,328 & 1,304 & 1,008 & 3,640 \\
\hline S-Sweden & 0 & 1,040 & 1,077 & 2,117 \\
\hline CZ-Czech Republic & 0 & 1,150 & 1,344 & 2,494 \\
\hline SLO-Slovenia & 1,994 & 920 & 897 & 3,811 \\
\hline PL-Poland & 944 & 1,015 & 1,148 & 3,107 \\
\hline BG-Bulgaria & 0 & 1,034 & 0 & 1,034 \\
\hline RUS-Russia & 2,636 & 1,325 & 806 & 4,767 \\
\hline NZ-New Zealand & 972 & 930 & 956 & 2,858 \\
\hline CDN-Canada & 0 & 882 & 0 & 882 \\
\hline RP-Philippines & 1,130 & 1,136 & 1,164 & 3,430 \\
\hline
\end{tabular}

\begin{tabular}{lrrrr}
\hline & \multicolumn{3}{c}{ Year of survey } & \\
\cline { 2 - 3 } Country & $\mathbf{1 9 9 1}$ & $\mathbf{1 9 9 8}$ & $\mathbf{2 0 0 8}$ & \multicolumn{1}{c}{ Total } \\
\hline IL-Israel & 891 & 1,167 & 1,138 & 3,196 \\
E-Spain & 0 & 1,835 & 2,071 & 3,906 \\
LV-Latvia & 0 & 1,032 & 890 & 1,922 \\
SK-Slovak Republic & 0 & 1,149 & 1,009 & 2,158 \\
F-France & 0 & 1,042 & 2,219 & 3,261 \\
CY-Cyprus & 0 & 888 & 888 & 1,776 \\
P-Portugal & 0 & 1,029 & 942 & 1,971 \\
RCH-Chile & 0 & 1,421 & 1,427 & 2,848 \\
D-Denmark & 0 & 1,087 & 1,583 & 2,670 \\
CH-Switzerland & 0 & 1,094 & 1,164 & 2,258 \\
B-Belgium & 0 & 0 & 1,130 & 1,130 \\
HR-Croatia & 0 & 0 & 2,668 & 2,668 \\
FIN-Finland & 0 & 0 & 838 & 838 \\
TR-Turkey & 0 & 0 & 1,379 & 1,379 \\
DO-Dominican Republic & 0 & 0 & 2,056 & 2,056 \\
MX-Mexico & 0 & 0 & 1,082 & 1,082 \\
ZA-South Africa & 0 & 0 & 2,648 & 2,648 \\
UA-Ukraine & 0 & 0 & 1,794 & 1,794 \\
UY-Uruguay & 0 & 0 & 1,001 & 1,001 \\
VZ-Venezuela & 0 & 0 & 857 & 857 \\
Total & 23,517 & 33,050 & 48,520 & 105,087 \\
\hline \hline
\end{tabular}

Note: In the survey waves 1991 and 1998, Israel was only considered one country case, while in the 2008 sample Israeli Jews and Israeli Arabs were counted as different regional cases. We regarded both groups as part of one country in line with the previous two waves. 
Table A-2.2: Descriptive statistics of variables in the sample.

\begin{tabular}{lrrrrr} 
Variable & N & Mean & Std. Dev. & Min. & Max. \\
\hline Country level & & & & & \\
GDP per capita/1000 & 105,087 & 17.48 & 9.40 & 1.42 & 42.24 \\
Ex-socialist country (no = ref.) & 105,087 & 0.28 & 0.45 & 0.00 & 1.00 \\
National religiosity & 105,087 & 3.08 & 0.77 & 1.46 & 4.70 \\
Gini Index & 105,087 & 32.46 & 7.94 & 22.28 & 60.61 \\
Year of survey & & & & & \\
$\quad 1991$ & 105,087 & 0.22 & 0.42 & 0.00 & 1.00 \\
$\quad 1998$ & 105,087 & 0.31 & 0.46 & 0.00 & 1.00 \\
2008 & 105,087 & 0.46 & 0.50 & 0.00 & 1.00 \\
Individual level & & & & & \\
Religious belief & 105,087 & 63.81 & 33.34 & 0.00 & 100.00 \\
Parents' rel. att. at resp. age 12 & 105,087 & 3.09 & 1.50 & 1.00 & 5.00 \\
Sex (female) & 105,087 & 0.54 & 0.50 & 0.00 & 1.00 \\
Age & 105,087 & 46.08 & 16.74 & 16.00 & 98.00 \\
Education (years) & 105,087 & 11.53 & 3.81 & 0.00 & 19.00 \\
Religion resp. was raised in & & & & & \\
$\quad$ Catholic & 105,087 & 0.47 & 0.50 & 0.00 & 1.00 \\
Protestant & 105,087 & 0.26 & 0.44 & 0.00 & 1.00 \\
Orthodox & 105,087 & 0.04 & 0.21 & 0.00 & 1.00 \\
$\quad$ Muslim & 105,087 & 0.02 & 0.15 & 0.00 & 1.00 \\
Other & 105,087 & 0.05 & 0.23 & 0.00 & 1.00 \\
$\quad$ None & 105,087 & 0.47 & 0.50 & 0.00 & 1.00 \\
\hline \hline
\end{tabular}




\section{Appendix III - Full model results}

Table A-3.1: Country-level and individual-level determinants of religious belief. Results of multilevel-analysis, ISSP 1991-2008).

\begin{tabular}{|c|c|c|c|c|c|c|c|c|c|c|}
\hline & \multicolumn{2}{|c|}{ Null Model } & \multicolumn{2}{|c|}{ Ind. Level only } & \multicolumn{2}{|c|}{ Nat. Rel. IA } & \multicolumn{2}{|c|}{ Ex-Soc. IA } & \multicolumn{2}{|c|}{ Ex-Soc. + Nat. Rel. IA } \\
\hline & Coef. & S.E. & Coef. & S.E. & Coef. & S.E. & Coef. & S.E. & Coef. & S.E. \\
\hline \multicolumn{11}{|l|}{ Country-level main effects } \\
\hline National religiosity & & & & & 2.12 & 1.67 & 1.12 & 1.65 & 2.02 & 1.63 \\
\hline Ex-socialist & & & & & -4.47 & 2.88 & $-5.53^{+}$ & 2.90 & $-5.02^{+}$ & 2.80 \\
\hline GDP/1000 & & & & & $-0.21 * * *$ & 0.06 & $-0.21 * * *$ & 0.06 & $-0.21 * * *$ & 0.06 \\
\hline Gini & & & & & $0.72 * * *$ & 0.12 & $0.72 * * *$ & 0.12 & $0.72^{* * *}$ & 0.12 \\
\hline \multicolumn{11}{|l|}{ Cross-level interactions } \\
\hline Nat. rel. X P. rel. att. & & & & & $-1.81^{*}$ & 0.75 & & & $-1.61 *$ & 0.81 \\
\hline Ex-soc. X P. rel. att. & & & & & & & $1.89 *$ & 0.86 & $1.01^{*}$ & 1.08 \\
\hline \multicolumn{11}{|l|}{ GDP X P. rel. att. } \\
\hline \multicolumn{11}{|l|}{ Gini X P. rel. att. } \\
\hline \multicolumn{11}{|l|}{ Individual-level variables } \\
\hline Parents' religious attendance & & & $6.35^{* * *}$ & 0.50 & $6.42 * * *$ & 0.46 & $5.85^{* * *}$ & 0.62 & $6.14^{* * *}$ & 0.53 \\
\hline Female & & & $8.27 * * *$ & 0.67 & $8.27 * * *$ & 0.67 & $8.27 * * *$ & 0.67 & $8.27^{* * *}$ & 0.67 \\
\hline Education years & & & $-0.72 * * *$ & 0.10 & $-0.72 * * *$ & 0.10 & $-0.72 * * *$ & 0.10 & $-0.72 * * *$ & 0.10 \\
\hline $\operatorname{Age}(* 10)$ & & & $0.72 * * *$ & 0.22 & $0.72 * * *$ & 0.22 & $0.72 * * *$ & 0.22 & $0.72 * * *$ & 0.22 \\
\hline $\operatorname{Age}^{2}(* 10)$ & & & $0.02 * * *$ & 0.01 & $0.02 * * *$ & 0.01 & $0.02 * * *$ & 0.01 & $0.02 * * *$ & 0.01 \\
\hline \multicolumn{11}{|l|}{$\begin{array}{l}\text { Religion of resp. upbringing } \\
\text { (Ref.: Catholic) }\end{array}$} \\
\hline Protestant & & & -1.33 & 1.70 & -1.34 & 1.70 & -1.33 & 1.70 & -1.33 & 1.70 \\
\hline Orthodox & & & 1.67 & 1.50 & 1.72 & 1.51 & 1.74 & 1.51 & 1.71 & 1.51 \\
\hline Muslim & & & $14.08 * * *$ & 2.94 & $14.08 * * *$ & 2.94 & $14.09 * * *$ & 2.94 & $14.08 * * *$ & 2.94 \\
\hline Other & & & 1.21 & 1.62 & 1.19 & 1.63 & 1.21 & 1.63 & 1.19 & 1.63 \\
\hline None & & & $-18.02 * * *$ & 2.12 & $-18.02 * * *$ & 2.12 & $-18.02 * * *$ & 2.12 & $-18.01 * * *$ & 2.12 \\
\hline Constant & $65.49 * * *$ & 2.57 & $62.95 * * *$ & 2.27 & $63.55^{* * *}$ & 1.66 & $63.84 * * *$ & 1.68 & $63.70 * * *$ & 1.66 \\
\hline
\end{tabular}

Notes: ${ }^{+} p \leq .10 ; * p \leq .05 ; * * p \leq 0.01 ; * * * \leq .001$; robust SEs, corrected for clustering in countries. 
Table A-3.2: Country-level and individual-level determinants of religious belief. Results of multilevel-analysis, ISSP 1991-2008).

\begin{tabular}{|c|c|c|c|c|c|c|c|c|c|c|}
\hline & \multicolumn{2}{|c|}{ GDP IA } & \multicolumn{2}{|c|}{ GDP + Nat. Rel. IA } & \multicolumn{2}{|c|}{ Gini IA } & \multicolumn{2}{|c|}{ Gini + Nat. Rel. IA } & \multicolumn{2}{|c|}{ All IA } \\
\hline & Coef. & S.E. & Coef. & S.E. & Coef. & S.E. & Coef. & S.E. & Coef. & S.E. \\
\hline \multicolumn{11}{|l|}{ Country-level main effects } \\
\hline National religiosity & 1.10 & 1.66 & 2.14 & 1.68 & 1.56 & 1.54 & 1.81 & 1.55 & 1.78 & 1.53 \\
\hline GDP/1000 & $-0.20 * * *$ & 0.06 & $-0.20 * * *$ & 0.06 & $-0.23 * * *$ & 0.06 & $-0.23 * * *$ & 0.06 & $-0.23 * * *$ & 0.05 \\
\hline Gini & $0.71 * * *$ & 0.12 & $0.72 * * *$ & 0.12 & $0.80 * * *$ & 0.10 & $0.80^{* * *}$ & 0.10 & $0.80 * * *$ & 0.10 \\
\hline Ex-soc. X P. rel. att. & & & & & & & & & 0.45 & 0.67 \\
\hline GDP X P. rel. att. & -0.01 & 0.03 & -0.01 & 0.03 & & & & & 0.02 & 0.03 \\
\hline Gini X P. rel. att. & & & & & $-0.30 * * *$ & 0.05 & $-0.29 * * *$ & 0.05 & $-0.29 * * *$ & 0.05 \\
\hline \multicolumn{11}{|l|}{ Individual-level variables } \\
\hline Parents' religious attendance & $6.35^{* * *}$ & 0.51 & $6.41^{* * *}$ & 0.47 & $6.50 * * *$ & 0.29 & $6.52^{* * * *}$ & 0.28 & $6.40 * * *$ & 0.32 \\
\hline \multicolumn{11}{|l|}{$\begin{array}{l}\text { Religion of resp. upbringing } \\
\text { (Ref.: Catholic) }\end{array}$} \\
\hline Protestant & -1.32 & 1.70 & -1.33 & 1.70 & -1.30 & 1.70 & -1.31 & 1.70 & -1.32 & 1.69 \\
\hline Orthodox & 1.75 & 1.51 & 1.72 & 1.51 & 2.00 & 1.56 & 1.95 & 1.55 & 1.94 & 1.54 \\
\hline Muslim & $14.10^{* * *}$ & 2.94 & $14.09 * * *$ & 2.94 & $14.25^{* * *}$ & 2.95 & $14.24 * * *$ & 2.95 & $14.22 * * *$ & 2.94 \\
\hline Other & 1.21 & 1.63 & 1.19 & 1.62 & 1.10 & 1.61 & 1.09 & 1.61 & 1.09 & 1.60 \\
\hline None & $-18.02 * * *$ & 2.12 & $-18.01 * * *$ & 2.12 & $-18.01 * * *$ & 2.15 & $-17.99 * * *$ & 2.15 & $-17.99 * * *$ & 2.13 \\
\hline Constant & $63.57 * * *$ & 1.68 & $63.56 * * *$ & 1.68 & $63.54 * * *$ & 1.63 & $63.57 * * *$ & 1.64 & $63.61 * * *$ & 1.61 \\
\hline
\end{tabular}

Notes: ${ }^{+} p \leq .10 ; * p \leq .05 ; * * p \leq 0.01 ; * * * p \leq .001 ;$ robust SEs, corrected for clustering in countries. 
Table A-3.1.1: Country-level and individual-level determinants of religious belief. Unstandardized and standardized coefficients.

\begin{tabular}{|c|c|c|c|c|c|c|c|c|c|c|}
\hline & \multicolumn{2}{|c|}{ Null Model } & \multicolumn{2}{|c|}{ Ind. Level only } & \multicolumn{2}{|c|}{ Nat. Rel. IA } & \multicolumn{2}{|c|}{ Ex-Soc. IA } & \multicolumn{2}{|c|}{ Ex-Soc. + Nat. Rel. IA } \\
\hline & Coef. & beta & Coef. & beta & Coef. & beta & Coef. & beta & Coef. & beta \\
\hline \multicolumn{11}{|l|}{ Country-level main effects } \\
\hline National religiosity & & & & & 2.12 & 0.05 & 1.12 & 0.03 & 2.02 & 0.05 \\
\hline Ex-socialist & & & & & -4.47 & -0.06 & $-5.53^{+}$ & -0.07 & $-5.02^{+}$ & -0.07 \\
\hline GDP/1000 & & & & & $-0.21 * * *$ & -0.06 & $-0.21 * * *$ & -0.06 & $-0.21 * * *$ & -0.06 \\
\hline Gini & & & & & $0.72 * * *$ & 0.17 & $0.72^{* * *}$ & 0.17 & $0.72 * * *$ & 0.17 \\
\hline \multicolumn{11}{|l|}{ Cross-level interactions } \\
\hline Nat. rel. X P. rel. att. & & & & & $-1.81^{*}$ & -0.06 & & & $-1.61 *$ & -0.05 \\
\hline Ex-soc. X P. rel. att. & & & & & & & $1.89 *$ & 0.05 & $1.01 *$ & 0.02 \\
\hline \multicolumn{11}{|l|}{ GDP X P. rel. att. } \\
\hline \multicolumn{11}{|l|}{ Gini X P. rel. att. } \\
\hline \multicolumn{11}{|l|}{ Individual-level variables } \\
\hline Parents' religious attendance & & & $6.35^{* * *}$ & 0.29 & $6.42 * * *$ & 0.29 & $5.85^{* * *}$ & 0.26 & $6.14^{* * *}$ & \\
\hline Female & & & $8.27 * * *$ & 0.12 & $8.27 * * *$ & 0.12 & $8.27^{* * *}$ & 0.12 & $8.27 * * *$ & 0.12 \\
\hline Education years & & & $-0.72 * * *$ & -0.08 & $-0.72 * * *$ & -0.08 & $-0.72 * * *$ & -0.08 & $-0.72 * * *$ & -0.08 \\
\hline Age $(* 10)$ & & & $0.72 * * *$ & 0.04 & $0.72 * * *$ & 0.04 & $0.72^{* * *}$ & 0.04 & $0.72 * * *$ & 0.04 \\
\hline $\operatorname{Age}^{2}(* 10)$ & & & $0.02 * * *$ & 0.02 & $0.02 * * *$ & 0.02 & $0.02 * * *$ & 0.02 & $0.02 * * *$ & 0.02 \\
\hline \multicolumn{11}{|l|}{$\begin{array}{l}\text { Religion of resp. upbringing } \\
\text { (Ref.: Catholic) }\end{array}$} \\
\hline Protestant & & & -1.33 & -0.02 & -1.34 & -0.02 & -1.33 & -0.02 & -1.33 & -0.02 \\
\hline Orthodox & & & 1.67 & 0.01 & 1.72 & 0.01 & 1.74 & 0.01 & 1.71 & 0.01 \\
\hline Muslim & & & $14.08 * * *$ & 0.06 & $14.08 * * *$ & 0.06 & $14.09 * * *$ & 0.06 & $14.08 * * *$ & 0.06 \\
\hline Other & & & 1.21 & 0.01 & 1.19 & 0.01 & 1.21 & 0.01 & 1.19 & 0.01 \\
\hline None & & & $-18.02 * * *$ & -0.19 & $-18.02 * * *$ & -0.19 & $-18.02 * * *$ & -0.19 & $-18.01 * * *$ & -0.19 \\
\hline Constant & $65.49 * * *$ & & $62.95 * * *$ & & $63.55^{* * *}$ & & $63.84 * * *$ & & $63.70 * * *$ & \\
\hline
\end{tabular}

Notes: ${ }^{+} p \leq .10 ; * p \leq .05 ; * * \leq 0.01 ; * * * p \leq .001 ;$ robust SEs, corrected for clustering in countries. 
Table A-3.2.2: Country-level and individual-level determinants of religious belief. Unstandardized and standardized coefficients.

\begin{tabular}{|c|c|c|c|c|c|c|c|c|c|c|}
\hline & \multicolumn{2}{|c|}{ GDP IA } & \multicolumn{2}{|c|}{ GDP + Nat. Rel. IA } & \multicolumn{2}{|c|}{ Gini IA } & \multicolumn{2}{|c|}{ Gini + Nat. Rel. IA } & \multicolumn{2}{|c|}{ All IA } \\
\hline & Coef. & beta & Coef. & beta & Coef. & beta & Coef. & beta & Coef. & beta \\
\hline \multicolumn{11}{|l|}{ Country-level main effects } \\
\hline National religiosity & 1.10 & 0.03 & 2.14 & 0.05 & 1.56 & 0.04 & 1.81 & 0.04 & 1.78 & 0.04 \\
\hline Ex-socialist & -4.51 & -0.06 & -4.50 & -0.06 & $-5.00^{+}$ & -0.07 & $-4.95^{+}$ & -0.07 & $-5.06^{+}$ & -0.07 \\
\hline GDP/1000 & $-0.20 * * *$ & -0.06 & $-0.20 * * *$ & -0.06 & $-0.23 * * *$ & -0.06 & $-0.23 * * *$ & -0.06 & $-0.23 * * *$ & -0.06 \\
\hline Gini & $0.71 * * *$ & 0.17 & $0.72 * * *$ & 0.17 & $0.80 * * *$ & 0.19 & $0.80 * * *$ & 0.19 & $0.80 * * *$ & 0.19 \\
\hline \multicolumn{11}{|l|}{ Cross-level interactions } \\
\hline Nat. rel. X P. rel. att. & & & $-1.82^{*}$ & -0.06 & & & $-0.72^{+}$ & -0.02 & -0.61 & -0.02 \\
\hline Ex-soc. X P. rel. att. & & & & & & & & & 0.45 & 0.01 \\
\hline GDP X P. rel. att. & -0.01 & -0.00 & -0.01 & -0.00 & & & & & 0.02 & -0.00 \\
\hline Gini X P. rel. att. & & & & & $-0.30 * * *$ & -0.11 & $-0.29 * * *$ & -0.11 & $-0.29 * * *$ & -0.11 \\
\hline \multicolumn{11}{|l|}{ Individual-level variables } \\
\hline Parents' religious attendance & $6.35^{* * *}$ & 0.29 & $6.41 * * *$ & 0.29 & $6.50 * * *$ & 0.29 & $6.52 * * *$ & 0.29 & $6.40 * * *$ & 0.29 \\
\hline Female & $8.27 * * *$ & 0.12 & $8.27 * * *$ & 0.12 & $8.26 * * *$ & 0.12 & $8.26 * * *$ & 0.12 & $8.26 * * *$ & 0.12 \\
\hline Education years & $-0.72 * * *$ & -0.08 & $-0.72 * * *$ & -0.08 & $-0.72 * * *$ & -0.08 & $-0.72 * * *$ & -0.08 & $-0.72 * * *$ & -0.08 \\
\hline Age & $0.07 * * *$ & 0.04 & $0.07 * * *$ & 0.04 & $0.07 * * *$ & 0.04 & $0.07 * * *$ & 0.04 & $0.07 * * *$ & 0.04 \\
\hline $\mathrm{Age}^{2}$ & $0.00 * * *$ & 0.02 & $0.00 * * *$ & 0.02 & $0.00 * * *$ & 0.02 & $0.00 * * *$ & 0.02 & $0.00 * * *$ & 0.02 \\
\hline \multicolumn{11}{|l|}{$\begin{array}{l}\text { Religion of resp. upbringing } \\
\text { (Ref.: Catholic) }\end{array}$} \\
\hline Protestant & -1.32 & -0.02 & -1.33 & -0.02 & -1.30 & -0.02 & -1.31 & -0.02 & -1.32 & -0.02 \\
\hline Orthodox & 1.75 & 0.01 & 1.72 & 0.01 & 2.00 & 0.01 & 1.95 & 0.01 & 1.94 & 0.01 \\
\hline Muslim & $14.10 * * *$ & 0.06 & $14.09 * * *$ & 0.06 & $14.25 * * *$ & 0.06 & $14.24 * * *$ & 0.06 & $14.22 * * *$ & 0.06 \\
\hline Other & 1.21 & 0.01 & 1.19 & 0.01 & 1.10 & 0.01 & 1.09 & 0.01 & 1.09 & 0.01 \\
\hline None & $-18.02 * * *$ & -0.19 & $-18.01 * * *$ & -0.19 & $-18.01 * * *$ & -0.19 & $-17.99 * * *$ & -0.19 & $-17.99 * * *$ & -0.19 \\
\hline Constant & $63.57 * * *$ & & $63.56 * * *$ & & $63.54 * * *$ & & $63.57 * * *$ & & $63.61 * * *$ & \\
\hline
\end{tabular}

Notes: ${ }^{+} p \leq .10 ; * p \leq .05 ; * * p \leq 0.01 ; * * * p \leq .001$; robust SEs, corrected for clustering in countries. 
Table A-3.3: Variance components and goodness of fit indicators.

\begin{tabular}{|c|c|c|c|c|c|c|c|c|c|c|}
\hline & Null model & $\begin{array}{l}\text { Ind. Level } \\
\text { only }\end{array}$ & $\begin{array}{l}\text { Nat. Rel. } \\
\text { IA }\end{array}$ & Ex-Soc. IA & $\begin{array}{c}\text { Ex-Soc. + } \\
\text { Nat. Rel. } \\
\text { IA } \\
\end{array}$ & GDP IA & $\begin{array}{c}\text { GDP + } \\
\text { Nat. Rel. } \\
\text { IA } \\
\end{array}$ & Gini IA & $\begin{array}{l}\text { Gini + Nat. } \\
\text { Rel. IA }\end{array}$ & All IA \\
\hline \multicolumn{11}{|l|}{ Variance components } \\
\hline $\begin{array}{l}\operatorname{Var}\left(\mathrm{u}_{\mathrm{j} 0}\right)-\text { Rand. } \\
\text { i'cept countries }\end{array}$ & $253.43 * * *$ & $135.14 * * *$ & $47.43 * * *$ & $47.67 * * *$ & $47.37 * * *$ & $48.22 * * *$ & $47.69 * * *$ & $44.16^{* * *}$ & $44.40 * * *$ & $44.17 * *$ \\
\hline $\begin{array}{l}\text { Var }\left(\mathrm{u}_{\mathrm{k} 0}\right)-\text { Rand. } \\
\text { i'cept years }\end{array}$ & $18.60 * * *$ & $10.04 * * *$ & $8.29 * * *$ & $8.30 * * *$ & $8.29 * * *$ & $8.31 * * *$ & $8.31 * * *$ & $8.41 * * *$ & $8.38 * * *$ & $8.34 * * *$ \\
\hline $\operatorname{Var}\left(\mathrm{e}_{\mathrm{ijk}}\right)-$ Res. Var. & $843.46^{* * *}$ & $645.30 * * *$ & $645.29 * * *$ & $645.29 * * *$ & $645.29 * * *$ & $645.28 * * *$ & $645.28 * * *$ & $645.15^{* * *}$ & $645.15 * * *$ & $645.14 * * *$ \\
\hline $\begin{array}{l}\operatorname{Var}\left(\mathrm{u}_{\mathrm{j} 1}\right)-\text { Rand. } \\
\text { slope P. rel. att. } \\
\operatorname{Cov}\left(\mathrm{u}_{\mathrm{j} 0}, \mathrm{u}_{\mathrm{j} 1}\right) \\
\text { intercept/slope }\end{array}$ & & $9.70 * * *$ & $7.97 * * *$ & $9.05 * * *$ & $7.78 * * *$ & $10.05 * * *$ & $8.20 * * *$ & $2.52 * * *$ & $2.32 * * *$ & $2.21 * * *$ \\
\hline covariance & & $26.69 * * *$ & 4.48 & -5.22 & -4.43 & -5.91 & -4.78 & -0.92 & -0.91 & -0.69 \\
\hline \multicolumn{11}{|c|}{ Goodness of fit indicators } \\
\hline Deviance & 1006662.0 & 978625.02 & 978595.18 & -978600.42 & 978594.26 & 978602.72 & 978594.62 & 978527.00 & 978522.88 & 978520.18 \\
\hline ICC(countries) & 0.23 & 0.18 & 0.08 & 0.08 & 0.08 & 0.08 & 0.08 & 0.07 & 0.07 & 0.07 \\
\hline ICC(years) & 0.02 & 0.01 & 0.01 & 0.01 & 0.01 & 0.01 & 0.01 & 0.01 & 0.01 & 0.01 \\
\hline $\mathrm{BIC}$ & 1006708.0 & 978810.0 & 978838.0 & 978843.2 & 978848.6 & 978845.5 & 978849.0 & 978769.8 & 978777.2 & 978797.7 \\
\hline $\begin{array}{l}\text { Number of } \\
\text { parameters }\end{array}$ & 4 & 16 & 21 & 21 & 22 & 21 & 22 & 21 & 22 & 24 \\
\hline
\end{tabular}

Notes: ${ }^{+} p \leq .10 ; * p \leq .05 ; * * p \leq 0.01 ; * * * p \leq .001$. All models contain $N x T=85$ country/year combinations, $N=41$ countries, and $n=105,807$ individuals. 
